OPEN ACCESS

Edited by:

Ligen Shi,

Zhejiang University, China

Reviewed by:

Jun Li,

Baylor College of Medicine

United States

Maria Concetta Miniaci,

University of Naples Federico II, Italy

${ }^{*}$ Correspondence:

William H. Griffith

whgriff@tamu.edu

Received: 26 February 2021 Accepted: 30 April 2021

Published: 28 May 2021

Citation:

Bang E, Tobery $A$

Montgomery KS, Fincher AS, Earnest DJ, Murchison DA and

Griffith WH (2021) Amitriptyline Decreases GABAergic Transmission in Basal Forebrain Neurons Using an

Optogenetic Model of Aging.

Front. Aging Neurosci. 13:673155.

doi: 10.3389/fnagi.2021.673155

\section{Amitriptyline Decreases GABAergic Transmission in Basal Forebrain Neurons Using an Optogenetic Model of Aging}

\author{
Eunyoung Bang, Angelika Tobery, Karienn S. Montgomery, Annette S. Fincher, \\ David J. Earnest, David A. Murchison and William H. Griffith*
}

Department of Neuroscience and Experimental Therapeutics, College of Medicine, Texas A\&M University Health Science Center, Bryan, TX, United States

The antidepressant drug amitriptyline is used in the treatment of clinical depression and a variety of neurological conditions such as anxiety, neuropathic pain disorders and migraine. Antidepressants are associated with both therapeutic and untoward effects, and their use in the elderly has tripled since the mid-1990s. Because of this widespread use, we are interested in testing the acute effects of amitriptyline on synaptic transmission at therapeutic concentrations well below those that block voltagegated calcium channels. We found that $3 \mu \mathrm{M}$ amitriptyline reduced the frequency of spontaneous GABAergic inhibitory postsynaptic currents (IPSCs) and reduced quantal content in mice at ages of 7-10 mo. and 23-25 mo., suggesting a presynaptic mechanism of action that does not diminish with age. We employed a reduced synaptic preparation of the basal forebrain (BF) and a new optogenetic aging model utilizing a bacterial artificial chromosome (BAC) transgenic mouse line with stable expression of the channelrhodopsin-2 (ChR2) variant H134R specific for GABAergic neurons [VGAT-ChR2(H134R)-EYFP]. This model enables optogenetic light stimulation of specific GABAergic synaptic terminals across aging. Age-related impairment of circadian behavior was used to confirm predictable age-related changes associated with this model. Our results suggest that low concentrations of amitriptyline act presynaptically to reduce neurotransmitter release and that this action is maintained during aging.

Keywords: amitriptyline, synaptic, patch-clamp, quantal analysis, optogenetics, basal forebrain, circadian, aging

\section{INTRODUCTION}

Amitriptyline (AMI) is a tricyclic antidepressant used for various neurological disorders such as anxiety, depression, neuropathic pain disorders and migraine (Baldessarini, 2006; Couch et al., 2011; Moore et al., 2015; Urquhart et al., 2018). Because of its diverse therapeutic applications, AMI continues to be used throughout life span, and overall antidepressant use among patients over 65 years of age has more than tripled from 1995 to 2005 (National Center for Health Statistics, 2007). Although the actions of AMI to block reuptake of norepinephrine and serotonin have been studied for many years, much less is known about the additional cellular mechanisms of AMI that 
may contribute to its therapeutic efficacy. For example, AMI acts to inhibit ion channels such as the voltage-gated sodium, calcium and potassium channels (Nicholson et al., 2002; Yan et al., 2010; Wu et al., 2012). AMI also acts as an antagonist of the serotonin, the $\alpha 1$-adrenergic, the histamine, and the muscarinic acetylcholine receptors (Richelson, 1979; Kachur et al., 1988; Nojimoto et al., 2010; Pandey et al., 2010; Liu et al., 2012). Moreover, it possesses neurotrophic activity by acting as an agonist of TrkA and TrkB receptor which BDNF activates (Jang et al., 2009). Many, but not all, of these actions to block ion channels occur at higher than therapeutic concentrations of approximately 3-6 $\mu \mathrm{M}$ (Glotzbach and Preskorn, 1982; Lavoie et al., 1990; Baldessarini, 2006). Importantly chronic low dose AMI, within the therapeutic range, is an effective therapy for lower back pain (Urquhart et al., 2018), reducing nicotineinduced increase in C-fiber excitability in humans (Freysoldt et al., 2009), and prevention of age-related impairment in the water maze task in rats (Yau et al., 2002). However, some human studies demonstrate the negative effects of AMI on cognitive function within the therapeutic ranges of depression treatment (Peck et al., 1979; Branconnier et al., 1982; Linnoila et al., 1983; Curran et al., 1988). Therefore, the purpose of the present study is to investigate whether therapeutic concentrations of AMI interfere with synaptic transmission in the basal forebrain (BF) using a new synaptic optogenetic model and whether these actions are maintained during aging.

The BF contains a heterogeneous population of cholinergic and non-cholinergic neurons located in the medial septum, diagonal band, nucleus basalis, ventral pallidum, substantia innominata, globus pallidus and the internal capsule (Wainer et al., 1985; Zaborszky et al., 1999; Hajszan et al., 2004; Manseau et al., 2005). These neurons play an important role in cognitive functions such as attention, arousal, and memory (see review, Záborszky et al., 2018) and our lab has been studying calcium homeostasis, voltage-gated calcium currents and synaptic transmission in these neurons across aging for many years (Griffith and Murchison, 1995; Murchison and Griffith, 1996, 1998, 2007; Murchison et al., 2009). Using a reduced synaptic preparation, we have shown that decreased GABAergic inhibitory synaptic transmission in BF is associated with age-related cognitive impairment in rats (Griffith et al., 2014). We have recently reproduced many of these earlier results in a new optogenetic aging model utilizing a bacterial artificial chromosome (BAC) transgenic mouse line with stable expression of the channelrhodopsin-2 (ChR2) variant H134R specific for GABAergic neurons [VGAT-ChR2(H134R)-EYFP] (Montgomery et al., in submission). In the present study, we have used this optogenetic aging model with wholecell voltage-clamp, $\mathrm{Ca}^{2+}$-sensitive fluorescent imaging and the reduced synaptic preparation to examine the effect of AMI on inhibitory synaptic transmission in the BF. The great advantage of the reduced synaptic preparation is that it is possible to selectively stimulate GABAergic nerve terminals on well-clamped isolated $\mathrm{BF}$ neurons. This model allows us to calculate relative changes in quantal content $(\mathrm{m})$ of transmitter release and identify presumed presynaptic functions. Finally, age-related changes in circadian wheel-running activity were used to further characterize the VGAT optogenetic mouse as a viable aging model.

\section{MATERIALS AND METHODS}

\section{Animals and Treatments}

Preliminary experiments to construct a concentration response curve for AMI inhibition of high voltage-activated (HVA) calcium currents utilized juvenile Fischer 344 rats. We have experience studying the physiology and pharmacology of $\mathrm{Ca}^{2+}$ currents in basal forebrain neurons of Fischer 344 rats (Murchison and Griffith, 1996, 1998), and therefore, used juvenile rats to confirm the concentration range for $\mathrm{Ca}^{2+}$ current inhibition by AMI. Pregnant F344 dams were obtained (Harlan, Indianapolis, IN) and allowed to give birth. Juveniles of both sexes were used between 10 and 30 days of age. For all other experiments we used VGAT-ChR2(H134R)-EYFP and wildtype (WT) C57 Bl/6 mice. Breeding pairs were purchased from Jackson Labs (Stock 014548; Zhao et al., 2011) and we established an aging colony where mice of all ages and both genotypes could be obtained. Mice were identified as WT or VGAT by standard tail-clip genotyping methods after weaning. Genotyping was done on a MJ PTC-100 Thermocycler (Bio-Rad Laboratories, Hercules, CA) using the EZ BioResearch Fast Tissue/Tail PCR Genotyping Kit (EZ BioResearch, St. Louis, MO) with value oligo primers from Thermo Fisher Scientific (Waltham, MA) and sequence from Jackson Lab (Bar Harbor, ME): transgene ( $400 \mathrm{bp}$ ): forward primer 11678: $5^{\prime}$-ACC CTT CTG TCC TTT TCT CC-3', reverse primer 10493: 5'-GCA AGG TAG AGC ATA GAG GG-3' and internal control (324 bp): forward primer oIMR7338: 5'-CTA GGC CAC AGA ATT GAA AGA TCT-3', reverse primer oIMR7339: 5'-GTA GGT GGA AAT TCT AGC ATC C-3'. Samples were run with Bulldog Bioflex S50 DNA ladder (Portsmouth, NH) on 2\% Agarose gel using 1 X TBE buffer with SYBR Safe DNA gel stain for $1.5 \mathrm{~h}$ and imaged either on a Flourchem Q or an Accuris Smartdoc.

For the data in Figure 3, to determine the concentration response relationship for $\mathrm{AMI}$ inhibition of spontaneous synaptic transmission, young mice were between 2 and 7 months of age $(N=23)$. For all other studies for age and AMI comparisons (Figures 4-6) all mice underwent circadian wheel-running prior to drug testing. For wheel-running behavior, young wildtype (WT, $N=6)$ and VGAT $(N=6)$ mice were 7-10 months while aged WT $(N=10)$ and VGAT $(N=10)$ mice were 2325 months. "N" refers to the number of mice, while " $n$ " is the number of neurons. All rodents were maintained in the AAALAC-accredited vivarium at the Texas A\&M University Health Science Center under controlled conditions $\left(22-25^{\circ} \mathrm{C}\right.$; lights 0700-1900 h; mouse chow and water ad lib) in accordance with policies of the Texas A\&M University Laboratory Animal Care Committee and NIH guidelines. TAMU animal protocol number 2019-0362.

\section{Immunohistochemistry}

Mice were deeply anesthetized with isoflurane and transcardially perfused with ice-cold phosphate-buffered saline (PBS, $0.01 \mathrm{M}$, 
$\mathrm{pH}$ 7.4) followed by a fixative, $4 \%$ paraformaldehyde (PFA) in PBS. Brains were quickly removed from the skull and post-fixed overnight in the same solution at $4^{\circ} \mathrm{C}$ followed by dehydration in $30 \%$ sucrose solution overnight at $4^{\circ} \mathrm{C}$. The brain was cut into $40-\mu \mathrm{m}$ coronal sections using a freezing microtome. Sections were washed 3 times in Tris-buffered saline (TBS, $100 \mathrm{mM}$ Tris$\mathrm{HCl}, 150 \mathrm{mM} \mathrm{NaCl}, \mathrm{pH} 7.5)$ and then permeabilized with TBST (0.1\% Triton X-100 in TBS) for $30 \mathrm{~min}$ at room temperature (RT). After permeabilization, sections were blocked (1.5 h at RT) with 5\% normal donkey serum in TBST and were incubated in primary antibody with blocking solution overnight at $4^{\circ} \mathrm{C}$. After incubation with primary antibody, sections were washed in TBS three times and incubated in secondary antibody with blocking solution for $2 \mathrm{~h}$ at RT followed by three-time wash in TBS. Lastly, they were mounted in Vectashield (Vector Laboratories, Burlingame, CA) and examined under a confocal laser-scanning microscope (FV1,200, Olympus, Shinjuku City, Tokyo). Antibodies targeting the following proteins were used: GFP (1:5,000; Abcam, Cambridge, MA) and NeuN (1:1,000; Millipore, Burlington, MA). The Alexa Fluor 488-conjugated goat anti-chicken IgY $(\mathrm{H}+\mathrm{L})$ antibody (1:300; Invitrogen, Carlsbad, CA) and Alexa Fluor 647-conjugated donkey anti-mouse IgG $(\mathrm{H}+\mathrm{L})$ antibody (1:300; Invitrogen, Carlsbad, CA) were used for secondary antibodies.

\section{Circadian Wheel Running Measurements}

For circadian measurements of wheel- running activity, mice were housed individually in cages equipped with running wheels. Animals were maintained on a standard $12 \mathrm{~h}$ light/12 h dark cycle (LD 12:12; lights-on at $0600 \mathrm{~h}$ ) and their circadian rhythms of wheel-running were continuously recorded for 30 days. Revolutions were summed and stored in 10-min bins, graphically depicted in actograms and analyzed using a computer running ClockLab data collection and analysis software (ActiMetrics, Evanston, IL). Entrainment and qualitative parameters of the activity rhythm were measured over the same interval for all animals. During entrainment to LD 12:12, the onset of activity for a given cycle was identified as the first bin during which an animal attained $10 \%$ of peak running-wheel revolutions (i.e. intensity). To measure angle of entrainment, least squares analyses was used to establish a regression line through the daily onsets of activity during the period of entrainment (30 days), and then the number of minutes before (positive) or after (negative) the time of lightsoff in the LD cycle $(1,800 \mathrm{~h})$ was determined for each animal. Total daily activity was calculated by averaging the number of wheel revolutions per 24 h over the 30 -day interval of analysis.

\section{Acutely Dissociated Neurons and Reduced Synaptic Preparation}

Rats and mice, were decapitated after isoflurane anesthetization and brain slices (400 $\mu \mathrm{m}$ for rats, $320 \mu \mathrm{m}$ for mice) were micro dissected to isolate the medial septum and nucleus of the diagonal band (MS/nDB), as described previously (Murchison and Griffith, 1996; Griffith et al., 2014). This tissue was kept suspended in a holding solution (mM): $140 \mathrm{NaCl}, 2.7 \mathrm{KCl}, 0.5$ $\mathrm{CaCl}_{2}, 1.2 \mathrm{MgCl}_{2}, 10 \mathrm{HEPES}$, and $33 \mathrm{D}$-glucose (pH 7.4 with
$\mathrm{NaOH}, 310-330$ mOsm) by a small magnetic stir bar and was continuously oxygenated with $100 \% \mathrm{O}_{2}$ in a holding chamber. Individual tissue pieces were triturated in a pair of fire-polished glass pipettes, and the dissociated cells were dispersed and allowed to settle onto the glass floor of a recording chamber containing bath solution (mM): $140 \mathrm{NaCl}, 2.7 \mathrm{KCl}, 2 \mathrm{CaCl}_{2}$, $1.2 \mathrm{MgCl}_{2}, 10 \mathrm{HEPES}$, and $33 \mathrm{D}$-glucose, then perfused at a rate of about $2 \mathrm{ml} / \mathrm{min}$. Experiments were performed at room temperature within $5 \mathrm{~h}$ of dispersal. For the rat wholecell $\mathrm{Ca}^{2+}$-current experiments and mouse fura- 2 experiments depicted in Figure 2, the pieces of BF slices were treated with trypsin (Sigma, type XI or type I, St. Louis, MO) as described previously (Murchison and Griffith, 1996, 1998). Importantly, for the synaptic studies in mice, no enzyme was used prior to dissociation in order to preserve presynaptic terminals on the reduced synaptic preparation (Griffith et al., 2014). This method is similar to that described by Akaike and Moorhouse (2003) to obtain a nerve-bouton preparation, however we have refined this technique to include aging neurons.

\section{Electrophysiology}

Whole-cell and perforated-patch voltage-clamp recordings were used. Whole-cell recording techniques were used for measuring spontaneous inhibitory postsynaptic currents (sIPSCs) and optically-evoked IPSCs (oIPSCs) while perforated-patch recordings were used for the calcium current experiment. Voltage-clamp recordings were performed using a Multiclamp 700B amplifier or Axopatch 200A (Molecular Devices, San Jose, CA), Digidata 1440A interface and pClamp 10 software (Molecular Devices, San Jose, CA). Membrane capacitance (pF) was obtained by digital cancelation of whole-cell capacitance transients. Recordings for sIPSCs and oIPSCs were made from a holding potential of $-60 \mathrm{mV}$, low-pass filtered at $2 \mathrm{kHz}$ and digitized at $10 \mathrm{kHz}$. Patch pipettes were pulled from glass capillary tubing (KG-33, 1.5 mm OD, King Precision Glass, Claremont, CA) on a Flaming/Brown P-87 pipette puller (Sutter Instrument ${ }^{\circledR}$, Novato, CA) with resistance 4-8 $\mathrm{M} \Omega$ when filled with a pipette solution. The internal pipette solution for whole-cell recordings contained $(\mathrm{mM})$ : $\mathrm{CsCl}, 130$; ethylene glycol-bis ( $\beta$-aminoethyl ether) $\mathrm{N}, \mathrm{N}, \mathrm{N}^{\prime}, \mathrm{N}^{\prime}$-tetraacetic acid (EGTA), 10; $\mathrm{MgCl}_{2}$, 2; HEPES, 10; Mg-ATP, 4; GTP, 0.1 ; pH 7.2 with $\mathrm{CsOH} ; 295-300 \mathrm{mOsm}$, as described previously (Murchison and Griffith, 1996). For perforated-patch recordings, the internal solution contained (mM): CsAc, 120; CsCl, 15; HEPES, 20; EGTA, 0.4; and amphotericin B (240 mg/ml), pH 7.2, 290-300 mOsm. AMI (Sigma, St. Louis, MO) was prepared as a $10 \mathrm{mM}$ stock solution in distilled water and diluted in external bath solution for each experiment just before use.

\section{Measuring Calcium Currents From Rat BF Neurons}

Acutely dissociated neurons from juvenile rats were used for these studies, as describe above in section "Acutely Dissociated Neurons and Reduced Synaptic Preparation." For experiments studying calcium currents, barium $(2 \mathrm{mM})$ was used as the charge carrier and voltage-clamp was obtained by the perforatedpatch method using amphotericin B $(240 \mathrm{mg} / \mathrm{ml})$ (Murchison et al., 2009). Amphotericin B was included in the patch pipette 


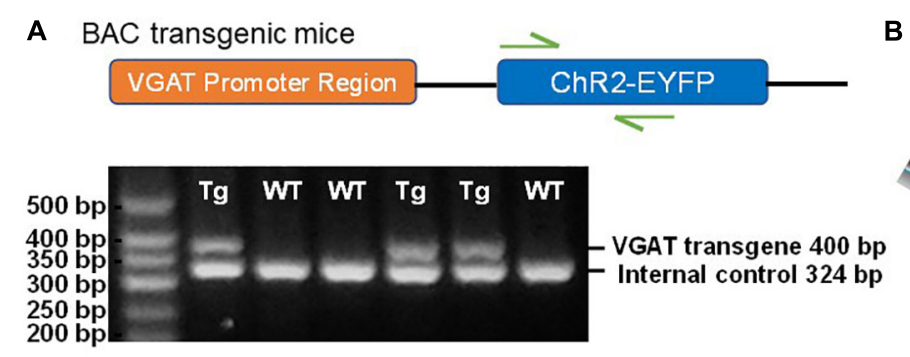

B Mechanically dissociated

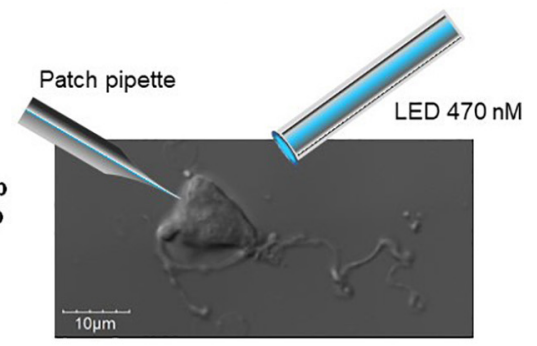

C

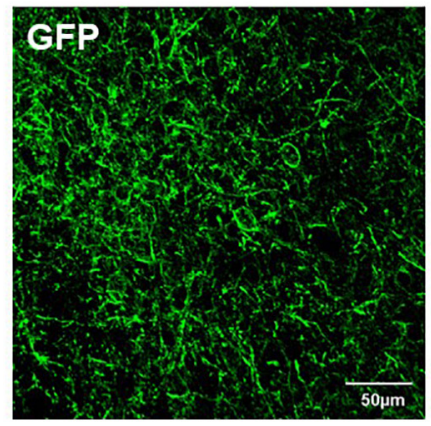

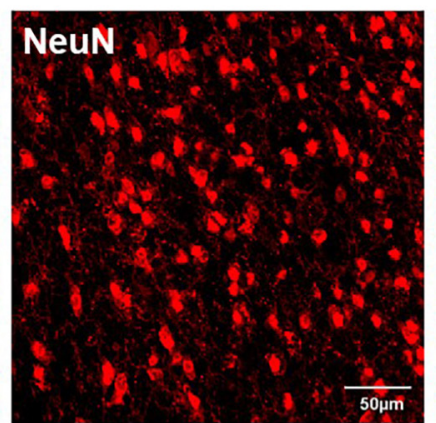

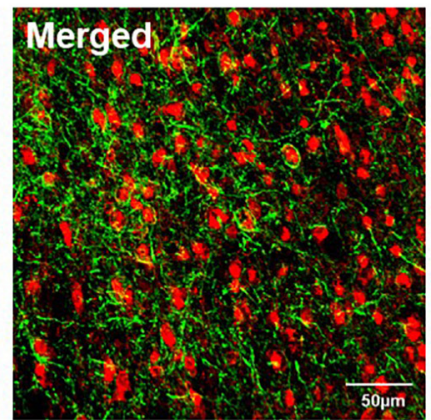

FIGURE 1 | Characterization of ChR2-EYFP expression in VGAT-ChR2(H134R)-EYFP transgenic mice. (A) Schematic representation of VGAT-ChR2-EYFP transgene (top) and an example of PCR gel electrophoresis (bottom). The first lane is the DNA size standard and the fragment size is given in base pairs on the left. The genotypes are described at the top of each lane. (B) The representative mechanically dissociated BF neuron with the illustrations of patch pipette and 470-nm LED light stimulation. (C) Confocal images of mouse BF slice show strong ChR2-EYFP expression in GABAergic neurons of VGAT-ChR2(H134R)-EYFP transgenic mice.

and neurons were allowed to dialyze $(\sim 4$ min after maximum perforation) prior to recording. Cells were held at $-70 \mathrm{mV}$ and a test pulse (to $-15 \mathrm{mV}, 90 \mathrm{~ms}$ duration) was applied every $20 \mathrm{~s}$. Barium replaces calcium as the charge carrier in the bath recording solution to prevent calcium-dependent processes and was used throughout the experiment as described in our previous studies (Murchison et al., 2009). Increasing concentrations of AMI were applied by focal drug barrel until a stable current was obtained. Currents were measured from $0 \mathrm{mV}$ to peak, and the percent inhibition of HVA calcium current by AMI was plotted.

\section{Optically-Induced Current Recordings and Quantal Content Analysis}

Neurons in the reduced synaptic preparation were mechanically dissociated from small sections of basal forebrain as describe above and dispersed onto a recording chamber. Optical stimulation was applied using 5-ms duration of $470 \mathrm{~nm}$ light at $15 \mathrm{~s}$ intervals using an optogenetic illumination system (DC2100, Thor Labs, Ann Arbor, MI) and 50-100 traces of optically-induced inhibitory postsynaptic currents (oIPSCs) were recorded. For the quantal content analysis, minimal stimulation was used in order to ensure a sufficient number of failures. LED intensity was controlled by adjusting the drive current $(1 \mathrm{~mA}$ 1A). Power density was calculated by dividing the measured power by the measured illuminated area using a PM200 optical power and energy meter (ThorLabs, Ann Arbor, MI) connected to an S120C photodiode sensor (ThorLabs, Ann Arbor, MI). Initial measurements using a $400 \mu \mathrm{m}$ cannula revealed a maximum power density of approximately $10 \mathrm{~mW} / \mathrm{mm}^{2}$, and a power density of $1.76 \mathrm{~mW} / \mathrm{mm}^{2}$ corresponding to $100 \mathrm{~mA}$ drive current. For the quantal content analysis, using the method of failures $\left(\mathrm{m}=\ln \left(\mathrm{N} / \mathrm{N}_{0}\right)\right)$ in the Poisson model, quantal content (m) was calculated where $\mathrm{N}$ is total number of stimuli, and $\mathrm{N}_{0}$ is the number of failures where stimulation failed to evoke a synaptic response.

\section{Electrophysiological Analysis}

Mini Analysis (6.0.7; Synaptosoft, Decatur, GA) and Clampfit 10 (Molecular Devices, San Jose, CA) software were employed for the analysis. The evoked response was calculated as the peak current over $20 \mathrm{~ms}$ from the time when response begins. Mean data were compared using a paired $t$-test with significance determined by $p<0.05$ (GraphPad, San Diego, CA). Values were expressed as mean \pm S.E.M.

\section{Calcium Imaging}

Standard fura-2 ratiometric microfluorimetry (Murchison and Griffith, 1998, 2007; Murchison et al., 2009) was used to measure intracellular calcium changes in enzyme-treated mouse BF neurons. Neurons were acutely dissociated and dispersed onto a cover slip and were loaded with ratiometric fluorescent $\mathrm{Ca}^{2+}$-indicator fura-2AM (1 $\mu \mathrm{M}$, Molecular Probes, Eugene, OR) from the bath for $12 \mathrm{~min}$ in the presence of $10 \mu \mathrm{M}$ pluronic acid (Invitrogen, Carlsbad CA) followed by 40$45 \mathrm{~min}$ washout to allow for fura de-esterification. The resulting fluorescence is equivalent to $\sim 100 \mu \mathrm{M}$ impermeable salt of fura-2 (pentapotassium salt, fura- $2 \mathrm{~K}^{+}{ }_{5}$ ). Fluorescence was recorded with $340 \mathrm{~nm}$ and $380 \mathrm{~nm}$ excitation and the 340/380 


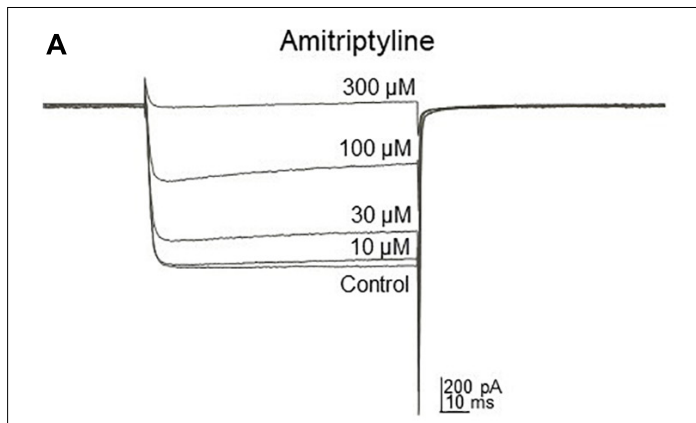

B

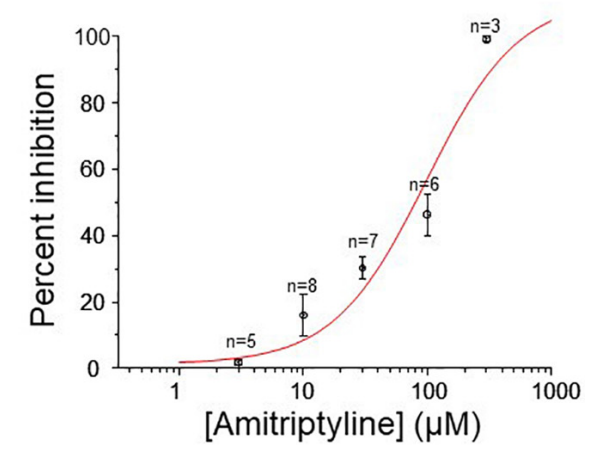

C
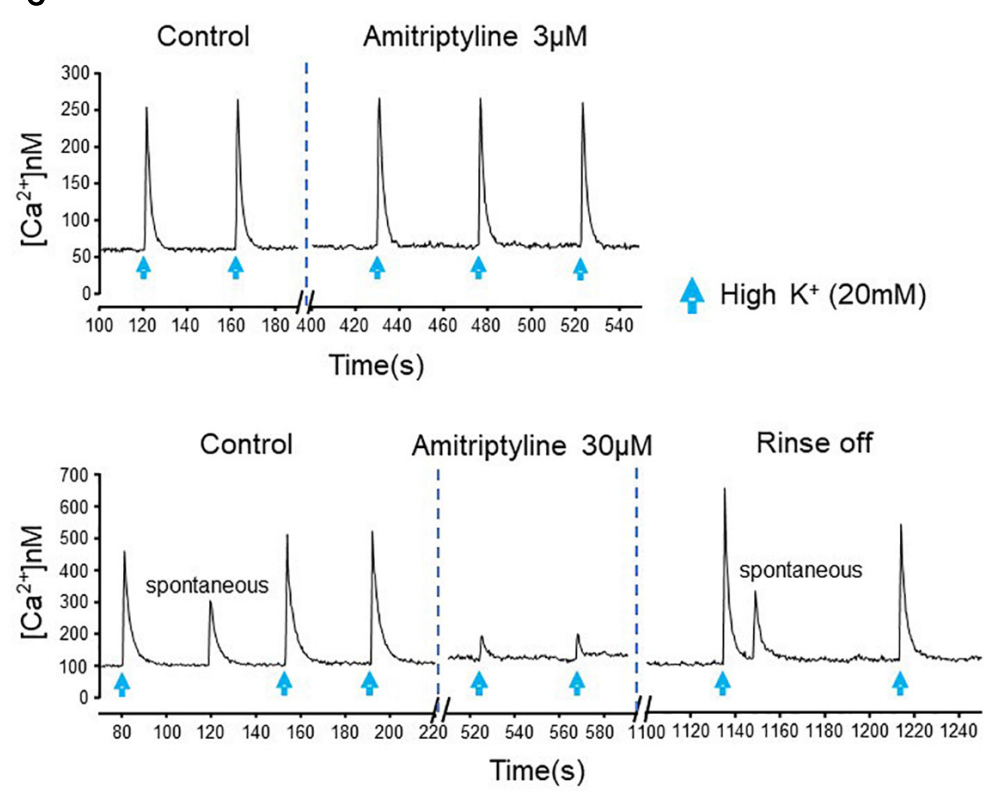

FIGURE 2 | AMI effect on calcium current and intracellular calcium transients. (A) Whole-cell perforated-patch voltage-clamp recordings of calcium currents from a rat $\mathrm{BF}$ neuron show reduced current amplitude in the presence of increasing concentrations of $\mathrm{AMI}$. Currents were elicited by a depolarizing test pulse to $-15 \mathrm{mV}$ $\left(V_{h}=-70 \mathrm{mV}, 20 \mathrm{~s}\right.$ between traces). (B) Cumulative concentration-response curve for AMl inhibition of calcium current in rat BF neurons. Percent inhibition of calcium current observed at five different concentrations $(3,10,30,100$, and $300 \mu \mathrm{M})$ was plotted ( \pm S.E.M.), yielding an EC 50 of $98.02 \mu \mathrm{M}$. (C) Fura-2 microfluorimetric recordings of intracellular calcium transients evoked by picospritzer application of 20 mM K+ (blue arrows, top panel: 600 ms, lower panel: 400 ms duration) show the effects of AMI on mouse BF neurons. The upper figure shows no effect of $3 \mu \mathrm{M}$ AMl on the amplitude of calcium transients. In a different cell, the lower figure shows reversible inhibition of calcium transient amplitude by $30 \mu \mathrm{M} \mathrm{AMI}(n=4)$. Spontaneous Ca ${ }^{2+}$ events are seen in the lower panel, as well.

ratio, which increases with increasing $\left[\mathrm{Ca}^{2+}\right]$ was calculated. In order to achieve an adequate sampling rate for the fura2 data shown in Figure 2, the pixels were binned and the fluorescent intensities were measured from a region of interest, centered on and smaller than the cell soma. Intracellular calcium concentrations $\left(\left[\mathrm{Ca}^{2+}\right]_{\mathrm{i}}\right)$ were estimated as described previously (Murchison and Griffith, 1998). $\mathrm{Ca}^{2+}$-transients $\left(\Delta\left[\mathrm{Ca}^{2+}\right]_{\mathrm{i}}\right)$ were triggered by focal picospritzer (Picospritzer II, General Valve, Fairfield NJ) application of recording solution with elevated $\left[\mathrm{K}^{+}\right](20 \mathrm{mM})$ solution (High $\left.\left[\mathrm{K}^{+}\right]\right)$. Fluorescent signals were recorded using a Sutter lambda DG-4 excitation switcher (Sutter Instrument ${ }^{\circledR}$, Novato, CA), a Hamamatsu ORCA flash2.8 CCD camera (Hamamatsu Photonics, Bridgewater Township, NJ), an Olympus IX70 fluorescent scope and Metafluor imaging software (Molecular Devices, San Jose, CA).

\section{Statistical Analysis}

Comparisons were performed using a paired $t$-test with significance determined by $p<0.05$ (GraphPad, San Diego, CA). Values are expressed as means \pm S.E.M. For wheel-running statistical analyses, raw data were analyzed using a two-way ANOVA to determine the significance of age and genotype effects on circadian properties and quantitative parameters of the activity rhythm. In each case, differences in circadian behavior were considered significant at $p<0.05$.

\section{RESULTS}

\section{Optogenetic Aging Model and Reduced Synaptic Preparation}

We recently demonstrated that the expression of ChR2 in mice carrying the VGAT-ChR2-EYFP transgene is functionally maintained across aging, thus this mouse line is useful for aging neuroscience (Montgomery et al., in submission). In mice hemizygous for VGAT-ChR2-EYFP BAC transgene, the ChR2-EYFP fusion protein is expressed in GABAergic neuronal populations by the mouse vesicular GABA transporter (VGAT) promoter on the BAC transgene (Figure 1A), which enables specific optical stimulation of GABAergic neurons. Whole brain coronal images showed strong ChR2-EYFP expression in a section of the BF (Figure 1C).

Our "reduced synaptic preparation" was designed to investigate synaptic physiology during aging with greater efficiency than in an aged slice preparation. This reduced preparation consists of acutely dissociated neurons that are not exposed to the usual proteolytic enzyme treatment and therefore retain functional presynaptic inputs on somas and proximal dendrites (Akaike and Moorhouse, 2003). Figure 1B shows an enzyme-free, acutely dissociated BF neuron and an illustration of the patch pipette and optogenetic light-stimulation. 


\section{Effects of AMI on Calcium}

The effect of AMI on whole-cell high-voltage-activated (HVA) calcium currents was investigated by applying a series of concentrations to acutely dissociated $\mathrm{BF}$ neurons from juvenile rats. The effect of AMI on calcium current inhibition was tested at the following five concentrations: $3 \mu \mathrm{M}(n=5), 10 \mu \mathrm{M}(n=8)$, $30 \mu \mathrm{M}(n=7), 100 \mu \mathrm{M}(n=6)$ and $300 \mu \mathrm{M}(n=3)$ with AMI inhibiting calcium currents by $1.87 \pm 0.65 \%, 16.02 \pm 6.37 \%$, $30.25 \pm 3.42 \%, 46.29 \pm 6.31 \%$ and $99.26 \pm 0.74 \%$, respectively (Figure 2A). Increasing concentrations were applied on the same neuron and the concentration-response curve for AMI is shown in Figure 2B. It is well known that high concentrations of AMI block voltage-gated $\mathrm{Ca}^{2+}$ channels (see Introduction), so the purpose of this experiment was to identify those concentrations of AMI below significant $\mathrm{Ca}^{2+}$ inhibition. The curve has a Hill coefficient of 1.2 and an $\mathrm{EC}_{50}$ (effective concentration for $50 \%$ inhibition) of approximately $100 \mu \mathrm{M}$.

To confirm that AMI acts in a similar manner on calcium signaling in the mouse, we used the ratiometric calcium-sensitive fluorescent probe fura-2 and induced robust intracellular calcium transients in acutely dissociated BF neurons by applying $20 \mathrm{mM}$ $\mathrm{KCl}\left(\right.$ High $\left[\mathrm{K}^{+}\right]$) by focal picospritzer. High $\left[\mathrm{K}^{+}\right]$depolarizes the membrane and activates voltage-gated $\mathrm{Ca}^{2+}$ channels. We then tested the ability of AMI to inhibit these transients (Figure 2C). AMI $(30 \mu \mathrm{M})$ significantly inhibited high $\left[\mathrm{K}^{+}\right]$-induced calcium transients by approximately $72 \%$ (Figure $2 \mathrm{C}$, bottom panel, control: $238 \pm 58.67 \mathrm{nM}$, and $30 \mu \mathrm{M}$ AMI: $65.5 \pm 19.85 \mathrm{nM}$, $\left.n=4,{ }^{*} p<0.05\right)$. On the other hand, $3 \mu \mathrm{M}$ AMI had no effect on transient amplitude which is consistent with the previous rat $\mathrm{BF}$ data showing very little inhibition of $\mathrm{Ca}^{2+}$ currents at that concentration. We next determined the concentration-response relationship for AMI inhibition of synaptic transmission.

\section{AMI Decreases Inhibitory Synaptic Transmission in Mouse BF Neurons}

To study synaptic transmission in mouse BF neurons, we used whole-cell voltage-clamp and the reduced synaptic preparation previously described in rats (Griffith et al., 2014). Briefly, this preparation utilizes acutely dissociated neurons, without enzyme treatment, resulting in isolated cells with functional synapses. The predominant spontaneous synaptic events in this preparation are GABAergic IPSCs. These currents are easily identified, from the very infrequent spontaneous EPSCs, by their larger amplitude (using $\mathrm{Cl}^{-}$filled electrodes, $\mathrm{V}_{\mathrm{h}}=-60 \mathrm{mV}$ ) and long-time course compared to the smaller and very fast spontaneous EPSCs (Griffith et al., 2014). We visually identified and measured spontaneous IPSCs in both WT and VGAT mice.

Six different concentrations of AMI were tested in young mouse BF neurons: $300 \mathrm{pM}(n=6), 1 \mathrm{nM}(n=5), 3 \mathrm{nM}$ $(n=10), 3 \mu \mathrm{M}(n=10), 10 \mu \mathrm{M}(n=8)$, and $30 \mu \mathrm{M}$ $(n=11)$. Figure 3A shows whole-cell voltage-clamp recordings of sIPSCs from the BF neurons in paired control and AMI for each concentration $\left(\mathrm{V}_{\mathrm{h}}=-60 \mathrm{mV}\right)$. The frequency of sIPSCs was significantly reduced in the presence of AMI at almost all concentrations tested (Figure 3B, top). The amplitude of sIPSCs was also significantly reduced by most concentrations of AMI
(Figure 3B, bottom, paired $t$-test, $\left.{ }^{*} p<0.05\right)$. We performed the remainder of the experiments using $3 \mu \mathrm{M}$ AMI because this concentration had minimal effect on calcium currents and transients but significantly reduced the frequency of sIPSCs. Furthermore, 3-6 $\mu \mathrm{M}$ AMI is considered a clinically relevant concentration for depression treatment (Glotzbach and Preskorn, 1982; Lavoie et al., 1990; Baldessarini, 2006).

\section{AMI Decreases Spontaneous IPSCs in Both Young and Aged BF Neurons}

The remaining experiments used both young (7-10 mo.) and aged (23-25 mo.) VGAT-ChR2-EYFP mice. In addition, these cohorts were monitored for wheel-running behavior in order to confirm the well-known age-related changes in patterns of circadian entrainment (Figure 7).

In young neurons, both mean frequency and mean amplitude of sIPSCs were significantly reduced by $3 \mu \mathrm{M}$ AMI. Figure $\mathbf{4 A}$ shows whole-cell voltage-clamp recordings of sIPSCs from young $\mathrm{BF}$ neurons in control and AMI $\left(\mathrm{V}_{\mathrm{h}}=-60 \mathrm{mV}\right)$. The mean sIPSC frequencies were $1.05 \pm 0.13 \mathrm{~Hz}$ for control and $0.24 \pm 0.07 \mathrm{~Hz}$ in AMI (left in Figure 4C, paired $t$-test, ${ }^{*} p<0.05$ ), and the inhibition normalized to control frequency is shown on the right (paired $t$-test, ${ }^{*} p<0.05$ ). For sIPSC amplitude, the means were $50.06 \pm 6.62 \mathrm{pA}$ in control and $31.37 \pm 4.44 \mathrm{pA}$ in AMI (left in Figure $4 \mathrm{E}$, paired $t$-test, $\left.{ }^{*} p<0.05\right)$, and the normalized change is shown on the right (paired $t$-test, ${ }^{*} p<0.05$ ). Figures $\mathbf{4 G , H}$ show the cumulative probability curves of young and aged sIPSC frequencies in control (black) and in $3 \mu \mathrm{M}$ AMI (red). These curves are significantly different by the Kolmogorov-Smirnov test $\left({ }^{*} p<0.01\right)$.

The same experiments were repeated in aged BF neurons (Figures 4B,D,F,H). Whole-cell voltage-clamp recordings $\left(\mathrm{V}_{\mathrm{h}}=-60 \mathrm{mV}\right)$ from the same neuron are shown in Figure 4B. Similar to young mice, the mean frequency of sIPSCs in aged $\mathrm{BF}$ neurons was significantly reduced by AMI (Figure 4D left, control: $0.92 \pm 0.28 \mathrm{~Hz}, 3 \mu \mathrm{M}$ AMI: $0.18 \pm 0.02 \mathrm{~Hz}$, paired $t$-test, $\left.{ }^{*} p<0.05\right)$. At the right on Figure $4 \mathrm{D}$, the normalized difference between control and AMI also was significant (paired $t$-test, ${ }^{*} p<0.05$ ). Although the mean amplitude of sIPSCs in the aged group was reduced in the presence of $3 \mu \mathrm{M}$ AMI, the change was not significant (left in Figure 4F, control: $53.75 \pm 9.32 \mathrm{pA}$, AMI: $35.9 \pm 4.58 \mathrm{pA}$, paired $t$-test, $p=0.07)$. The normalized change in the sIPSC amplitude between control and AMI in aged $\mathrm{BF}$ neurons also was not significant (Figure $4 \mathrm{~F}$ right, paired $t$-test, $p=0.11$ ). Despite the lack of significant effect of $3 \mu \mathrm{M}$ AMI on aged sIPSC amplitude, the reduction of both young and aged sIPSC frequency suggests that AMI remains efficacious during aging.

\section{AMI Decreases Light-Induced oIPSCs in Both Young and Aged BF Neurons}

To examine further synaptic mechanisms of AMI on inhibitory synaptic transmission, light-induced oIPSCs were measured before and after treatment with $3 \mu \mathrm{M}$ AMI in BF neurons from young and aged VGAT mice. As seen in superimposed voltage-clamp (Vh $=-60 \mathrm{mV})$ recordings in Figure 5A, AMI 

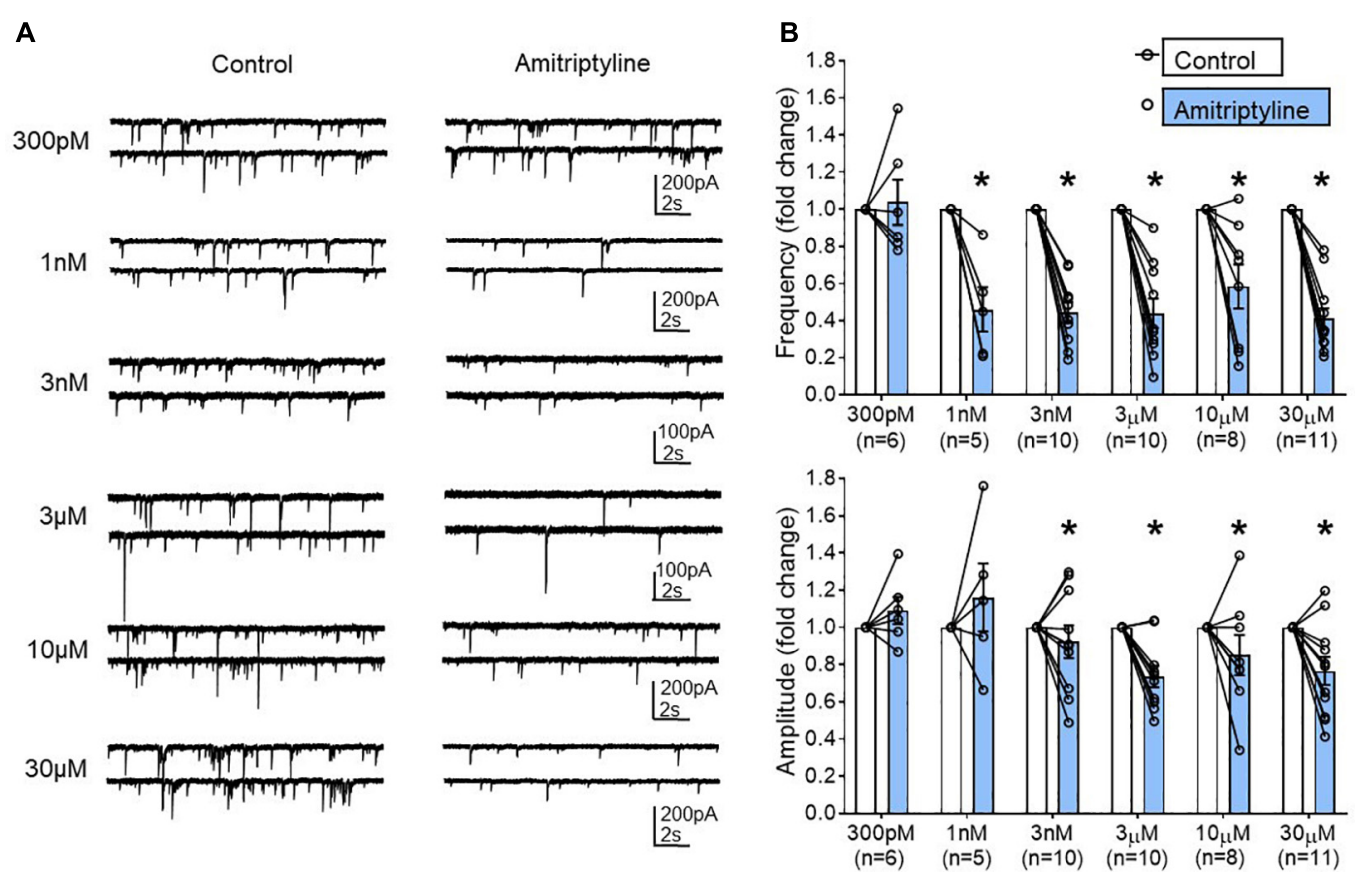

FIGURE 3 | Concentration-dependent changes in the frequency and amplitude of spontaneous IPSCs using a reduced synaptic preparation of BF neurons. (A) Representative whole-cell voltage-clamp recordings ( $\mathrm{h}=-60 \mathrm{mV}$ ) from young BF neurons in control (left) and AMl (right). Concentrations are shown to the left and each neuron only received one concentration of AMI. Frequency and amplitude of sIPSCs were decreased in a concentration-dependent manner by application of AMI. (B) Summary data showing the normalized frequency change in AMl (top, $300 \mathrm{pM}: 1.038 \pm 0.123,1 \mathrm{nM}$ : $0.460 \pm 0.120,3 \mathrm{nM}: 0.44 \pm 0.06,3 \mu \mathrm{M}$ : $0.44 \pm 0.08,10 \mu \mathrm{M}: 0.58 \pm 0.12,30 \mu \mathrm{M}: 0.41 \pm 0.06)$ and normalized amplitude change in AMl (bottom, $300 \mathrm{pM}: 1.09 \pm 0.07,1 \mathrm{nM}: 1.11 \pm 0.16,3 \mathrm{nM}:$ $0.92 \pm 0.09,3 \mu \mathrm{M}: 0.74 \pm 0.06,10 \mu \mathrm{M}: 0.85 \pm 0.11,30 \mu \mathrm{M}: 0.77 \pm 0.07$ ). Results are presented as mean \pm SEM. Individual cells (n) were paired for control and AMI (paired $t$-test, ${ }^{\star} p<0.05$ ). $N=23$ mice.

significantly decreased the amplitude of light-induced (470 nm, $5 \mathrm{~ms}$, constant intensity at blue arrow) oIPSCs in young BF neurons (left in Figure 5C, control: $109.3 \pm 19.05$ pA, AMI: $65.85 \pm 14.75 \mathrm{pA}$, paired $t$-test, $\left.{ }^{*} p<0.05\right)$ and the normalized amplitude (Figure 5C right, paired $t$-test, ${ }^{*} p<0.05$ ). Parallel experiments on oIPSCs using BF neurons from aged VGAT mice are seen in Figures 5B,D. Similarly, the amplitude of lightinduced oIPSC (Figure 5B) was significantly decreased by 3 $\mu \mathrm{M}$ AMI (left in Figure 5D, control: $136 \pm 37.88 \mathrm{pA}, 3 \mu \mathrm{M}$ AMI: $73.8 \pm 25.83 \mathrm{pA}$, paired $t$-test, $\left.{ }^{*} p<0.05\right)$. The normalized amplitude change is shown on the right of Figure 5D (paired $t$-test, $\left.{ }^{*} p<0.05\right)$. In Figures 5A,B, the superimposed gray traces represent 50 repetitions of the stimulus and the black trace is the average. Failures were not included in the measurement of the mean amplitudes.

To investigate further a possible presynaptic contribution of AMI to reduced oIPSCs, we performed quantal analysis using the method of failures. Quantal content $(\mathrm{m})$ was determined by $\mathrm{m}=\ln \left(\mathrm{N} / \mathrm{N}_{0}\right)$ as described in the methods. The power of this analysis is that no assumptions concerning synaptic number are necessary. Figures 6A,B show that minimal light stimulation (5 ms, blue arrow) generates both light-evoked currents and failures in both young and aged neurons. In the presence of AMI (3 $\mu \mathrm{M})$, the number of failures increased in both age groups. Analysis revealed that quantal content was significantly decreased by $3 \mu \mathrm{M}$ AMI in both young (left in Figure 6C, $\mathrm{m}=2.46 \pm 0.32$ for control and $0.54 \pm 0.11$ for AMI) and aged (left in Figure 6D, $\mathrm{m}=1.61 \pm 0.47$ for control and $0.26 \pm 0.10$ for AMI; paired $t$-test, $\left.{ }^{*} p<0.05\right)$. The normalized fold change in quantal content between control and AMI is shown to the right in Figures 6C,D (paired $t$-test, ${ }^{*} p<0.05$ ).

\section{Effect of Age on Daily Circadian Wheel-Running Entrainment}

For our electrophysiology experiments described above using VGAT mice (Figures 4-6), we utilized the well characterized circadian wheel-running entrainment model to validate our optogenetic aging model. During exposure to LD 12:12, entrainment of the activity rhythm was observed in all WT and VGAT mice. Representative actograms of young and aged animals from both WT (Figure 7A) and VGAT (Figure 7B) mice are shown and constitute the raw data from which the analysis (Figures 7C-E) was conducted. During entrainment to $\mathrm{LD} 12: 12$, young and aged mice of both genotypes were distinguished by robust differences in the total amount of daily wheel-running activity. Daily activity levels (wheel revolutions/24 h) were significantly and up to 8-fold greater in young WT and VGAT mice compared to aged subjects (Figure 7C, two-way ANOVA, age effect; F $\left.(1,28)=51.02,{ }^{*} p<0.0001\right)$. No effect of genotype was observed in daily wheel-running activity [two-way ANOVA, genotype effect; $F(1,28)=0.85, p=0.36$ ]. In both WT 
A

Young
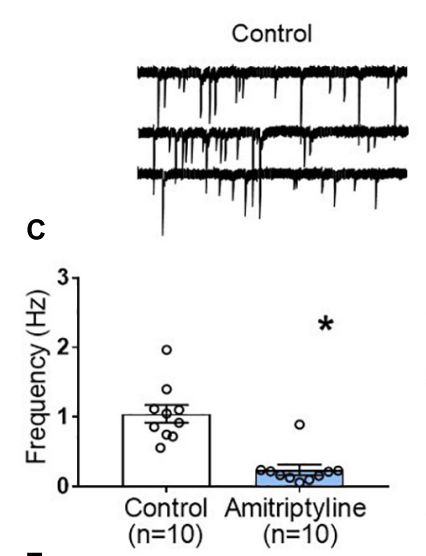

E

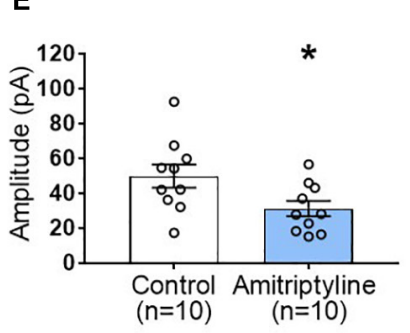

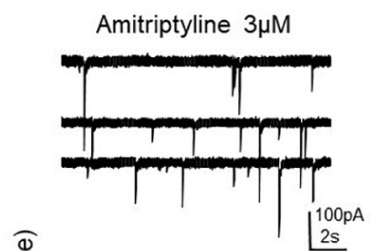
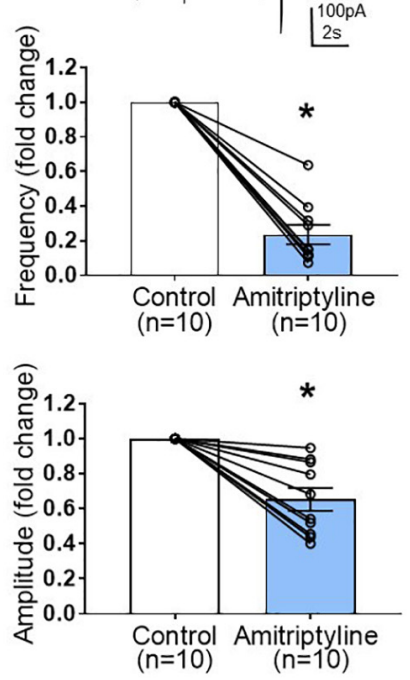

B

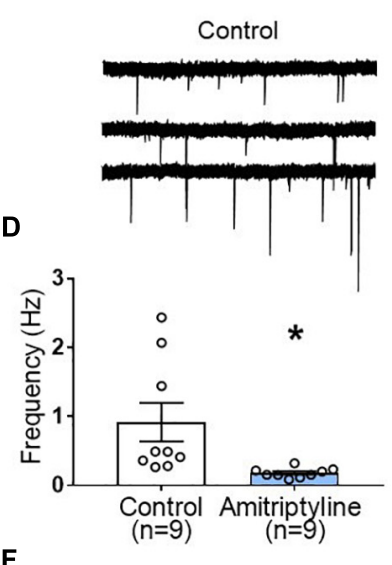

$\mathbf{F}$

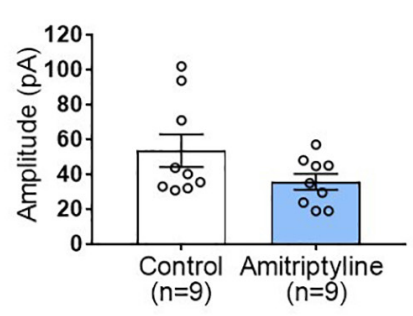

Aged
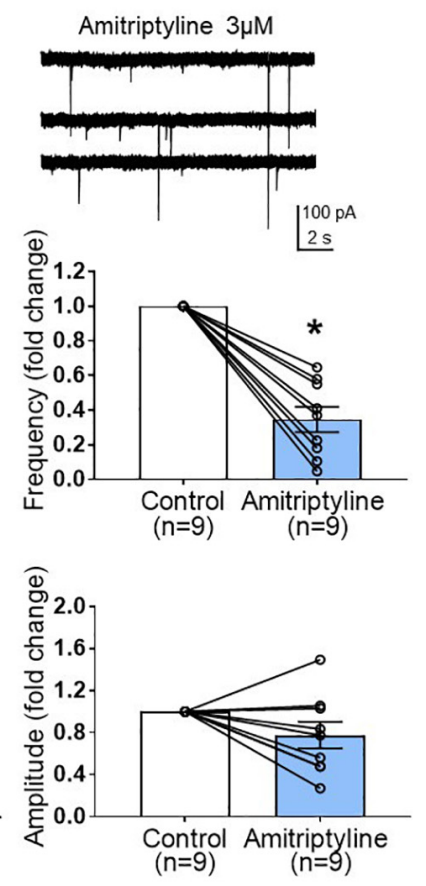

H

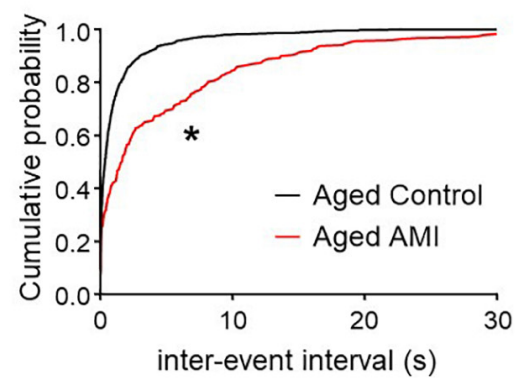

FIGURE 4 | The effect of AMI ( $3 \mu \mathrm{M})$ on spontaneous IPSC frequency and amplitude in BF neurons from young and aged VGAT mice using the reduced synaptic preparation. Representative whole-cell voltage-clamp recordings $\left(V_{h}=-60 \mathrm{mV}\right.$ ) from a young (A) and aged (B) BF neuron in control (left) and $3 \mu \mathrm{M}$ AMI (right). (C) Scatter plots with mean \pm SEM of frequency (left panel, $1.05 \pm 0.13 \mathrm{~Hz}$ for control, $0.24 \pm 0.07 \mathrm{~Hz}$ in $3 \mu \mathrm{M} \mathrm{AMl}$, paired $t$-test, ${ }^{*} p<0.05$ ) and graph of normalized fold change in frequency (right panel, $0.24 \pm 0.06$ for $3 \mu \mathrm{M} \mathrm{AMl}$, paired $t$-test, ${ }^{*} p<0.05$ ) show that AMl decreases the frequency of sIPSCs in young BF neurons. (D) Scatter plots with mean \pm SEM of frequency (left, control: $0.92 \pm 0.28 \mathrm{~Hz}, 3 \mu \mathrm{M} \mathrm{AMl}: 0.18 \pm 0.02 \mathrm{~Hz}$, paired $t$-test, ${ }^{*} p<0.05$ ) and graph of normalized fold change in frequency (right, $3 \mu \mathrm{M}$ AMI: $0.35 \pm 0.07$, paired $t$-test, ${ }^{*} p<0.05$ ) show that AMI decreases the frequency of sIPSCs in aged BF neurons. (E) Scatter plots with mean \pm SEM of amplitude (left panel, $50.06 \pm 6.62 \mathrm{pA}$ in control, $31.37 \pm 4.44 \mathrm{pA}$ in $3 \mu \mathrm{M}$ AMl, paired $t$-test, ${ }^{*} p<0.05$ ) and graph of normalized fold change in amplitude (right panel, $0.65 \pm 0.07$ in $3 \mu \mathrm{M}$ AMl, paired $t$-test, ${ }^{*} p<0.05$ ) show that AMl decreases the amplitude of sIPSCs in young BF neurons. (F) Scatter plots with mean \pm SEM of amplitude (left, control: $53.75 \pm 9.32$ pA, $3 \mu \mathrm{M}$ AMI: $35.9 \pm 4.58 \mathrm{pA}$, paired $t$-test, $p=0.07$ ) and graph of normalized fold change in amplitude (right, $3 \mu \mathrm{M}$ AMI: $0.78 \pm 0.13$, paired $t$-test, $p=0.11$ ) show that AMI did not significantly alter the amplitude of sIPSCs in aged BF neurons. (G) Cumulative probability plots of sIPSC inter-event intervals in young mouse BF neurons $(n=10)$. (H) Cumulative probability plots of sIPSC inter-event intervals in aged mouse BF neurons $(n=9)$. In AMl, the cumulative probability curves were significantly different from control $\left({ }^{*} p<0.01, \mathrm{~K}-\mathrm{S}\right.$ test). N $=5$ young and $N=5$ aged mice.

and VGAT mice, the young and aged cohorts were characterized by clear differences in their patterns of circadian entrainment. In the young mice, daily onsets of activity occurred near or shortly after lights-off such that the average phase angle $(\Psi)$ between the activity onsets and the offset of the photoperiod was $-7.70 \pm 2.63$ for WT and $-4.97 \pm 0.97 \mathrm{~min}$ for VGAT (Figure 7D). In contrast, the activity rhythms of aged mice were distinguished by an altered phase angle of entrainment to LD 12:12 such that their daily onsets of activity were delayed and occurred at later times relative to young animals, commencing more than 20 min after lights-off for most animals (Figures 7A,B,D). In the aged WT and VGAT groups, the average phase angles were $28.76 \pm 3.94$ and $-30.93 \pm 3.57 \mathrm{~min}$, respectively. These values were significantly greater than those observed in young animals for each genotype [Figure 7D, two-way ANOVA, age effect; $F$ (1, $\left.28)=41.74,{ }^{*} p<0.0001\right]$. There was no effect of genotype on phase angle of activity [two-way ANOVA, effect of genotype; $F(1$, $28)=0.01, p=0.95]$. In addition to the delayed onsets of daily 


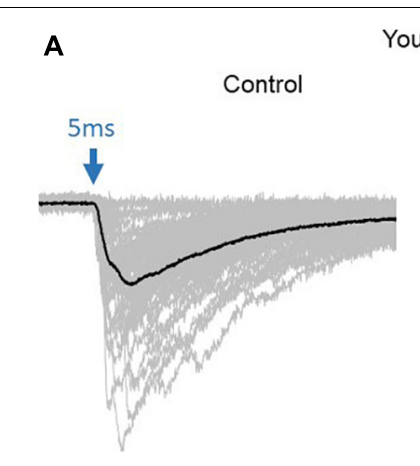

C

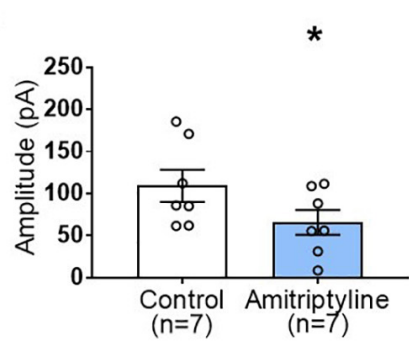

Young

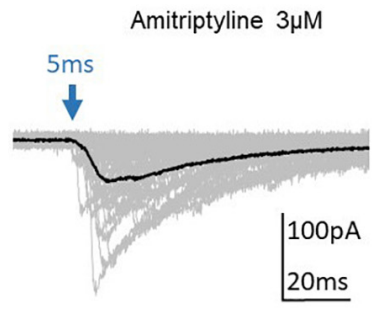

B

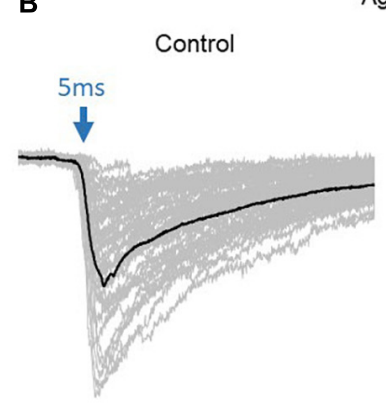

Aged

D
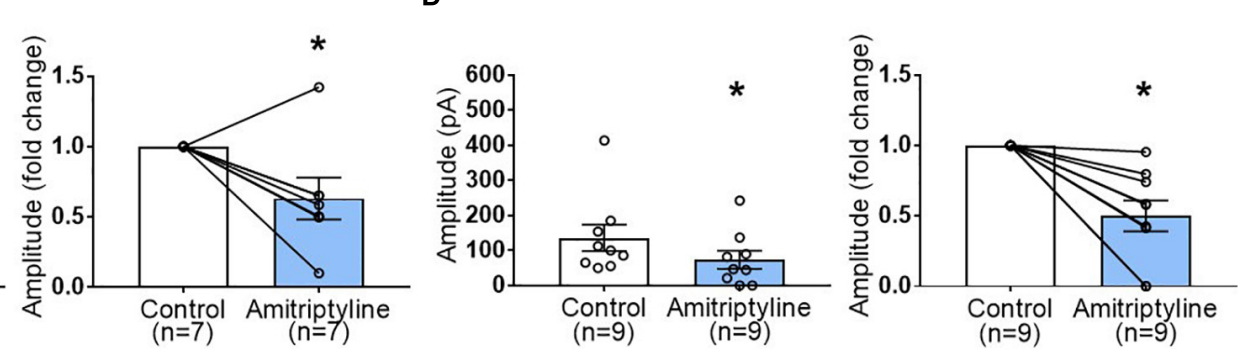

FIGURE 5 | The effect of AMI (3 $\mu \mathrm{M}$ ) on light-induced optical IPSC (oIPSC) amplitude in BF neurons of young and aged VGAT mice in the reduced synaptic preparation. (A,B) Superimposed (50 traces) whole-cell voltage-clamp recordings $\left(V_{h}=-60 \mathrm{mV}\right.$ ) of evoked olPSCs from a young (A) and an aged (B) BF neuron in control (left) and $3 \mu \mathrm{M}$ AMI (right). The evoking stimulus was a $5 \mathrm{~ms}$ pulse of $470 \mathrm{~nm}$ light at constant intensity (blue arrow). The black trace represents the mean olPSC and failures were not included in the calculation. (C) Scatter plots with mean data \pm SEM of olPSC amplitude (left panel, control: $109.3 \pm 19.05$ pA, $3 \mu$ M AMl: $65.85 \pm 14.75 \mathrm{pA}$, paired $t$-test, $\left.{ }^{*} p<0.05\right)$ and normalized fold change of olPSC amplitude $\left(3 \mu \mathrm{M} \mathrm{AMI:} 0.63 \pm 0.15\right.$, paired $t$-test, $\left.{ }^{*} p<0.05\right)$ show that AMl significantly decreases the amplitude of light-induced olPSCs in young BF neurons compared to control. (D) Scatter plots with mean \pm SEM of olPSC amplitude (left panel, control: $136 \pm 37.88$ pA, $3 \mu \mathrm{M}$ AMI: $73.8 \pm 25.83$ pA, paired $t$-test, $\left.{ }^{\star} p<0.05\right)$ and normalized fold change of olPSC amplitude $(3 \mu \mathrm{M}$ AMI: $0.50 \pm 0.11$, paired $t$-test, ${ }^{*} p<0.05$ ) show that AMl significantly decreases the amplitude of light-induced olPSCs in aged BF neurons. $N=5$ young and $N=4$ aged mice.

activity, aged WT and VGAT animals showed unstable patterns of entrainment to LD $12: 12$ as indicated by high variability in the timing of their activity onsets between successive days (Figures 7A,B,E). During exposure to LD 12:12, the activity onsets in individual aged WT and VGAT mice occurred at (earlier or later) times that differed on average, respectively, by $54.88 \pm 5.70$ and $61.21 \pm 6.49 \mathrm{~min}$ from the preceding day. Whereas the average day-to-day variability in activity onset times of young animals was only $18.38 \pm 5.03$ (WT) and $24.33 \pm 5.84$ (VGAT) minutes (Figure 7E). The values for day-to-day variation in the onsets of activity in the aged WT and VGAT groups were significantly greater [two-way ANOVA, age effect; $F(1$, $\left.28)=33.29,{ }^{*} p<0.0001\right]$ than those observed in their young counterparts. No significant difference in day-to-day variability in activity onset times was observed between age-matched WT and VGAT mice [two-way ANOVA, effect of genotype; $F(1$, 28) $=0.93, p=0.34]$.

\section{DISCUSSION}

In the present study, we show that therapeutic concentrations of AMI decrease spontaneous and light-evoked IPSCs in BF neurons at concentrations below those that block $\mathrm{HVA} \mathrm{Ca}{ }^{2+}$ currents. Importantly, this synaptic inhibition is preserved during aging. The therapeutic concentrations of AMI for the treatment of depression are 3-6 $\mu \mathrm{M}$ (Glotzbach and Preskorn, 1982; Lavoie et al., 1990), while lower concentrations are also effective for chronic pain and migraine (Riediger et al., 2017; Urquhart et al., 2018; Suga et al., 2019). These therapeutic actions of AMI are maintained in the elderly (Barber and Gibson, 2009). Our data suggest that inhibition of GABAergic synaptic transmission may be one of the mechanisms by which AMI acts therapeutically across aging. In our model, a low concentration of AMI, in the therapeutic range, reduced inhibitory synaptic transmission, whereas higher concentrations were required to block HVA $\mathrm{Ca}^{2+}$ currents and high $\mathrm{K}^{+}$induced intracellular $\mathrm{Ca}^{2+}$ transients.

AMI has a broad profile of pharmacological actions, including inhibition of biogenic amine reuptake, antagonism of serotonin, muscarinic, $\alpha 1$-adrenergic, and histamine receptors (Richelson, 1979; Kachur et al., 1988; Pandey et al., 2010; Nojimoto et al., 2010; Liu et al., 2012). It also acts to block $\mathrm{Ca}^{2+}$ and $\mathrm{Na}^{+}$channels (Brau et al., 2001; Nicholson et al., 2002; Yan et al., 2010; Wu et al., 2012). Additional actions of AMI are described for the NMDA receptor ion channel complex that may contribute to efficacy against neuropathic pain, including the enhancement of $\mathrm{Ca}^{2+}$-dependent receptor desensitization and acting as an open channel blocker of NMDARs (Stepanenko et al., 2019). The enhancement of NMDA receptor desensitization shows a strong dependence on extracellular $\left[\mathrm{Ca}^{2+}\right]$ concentrations with an e-fold shift in $\mathrm{IC}_{50}$ achieved by a $\left[\mathrm{Ca}^{2+}\right]$ change of 


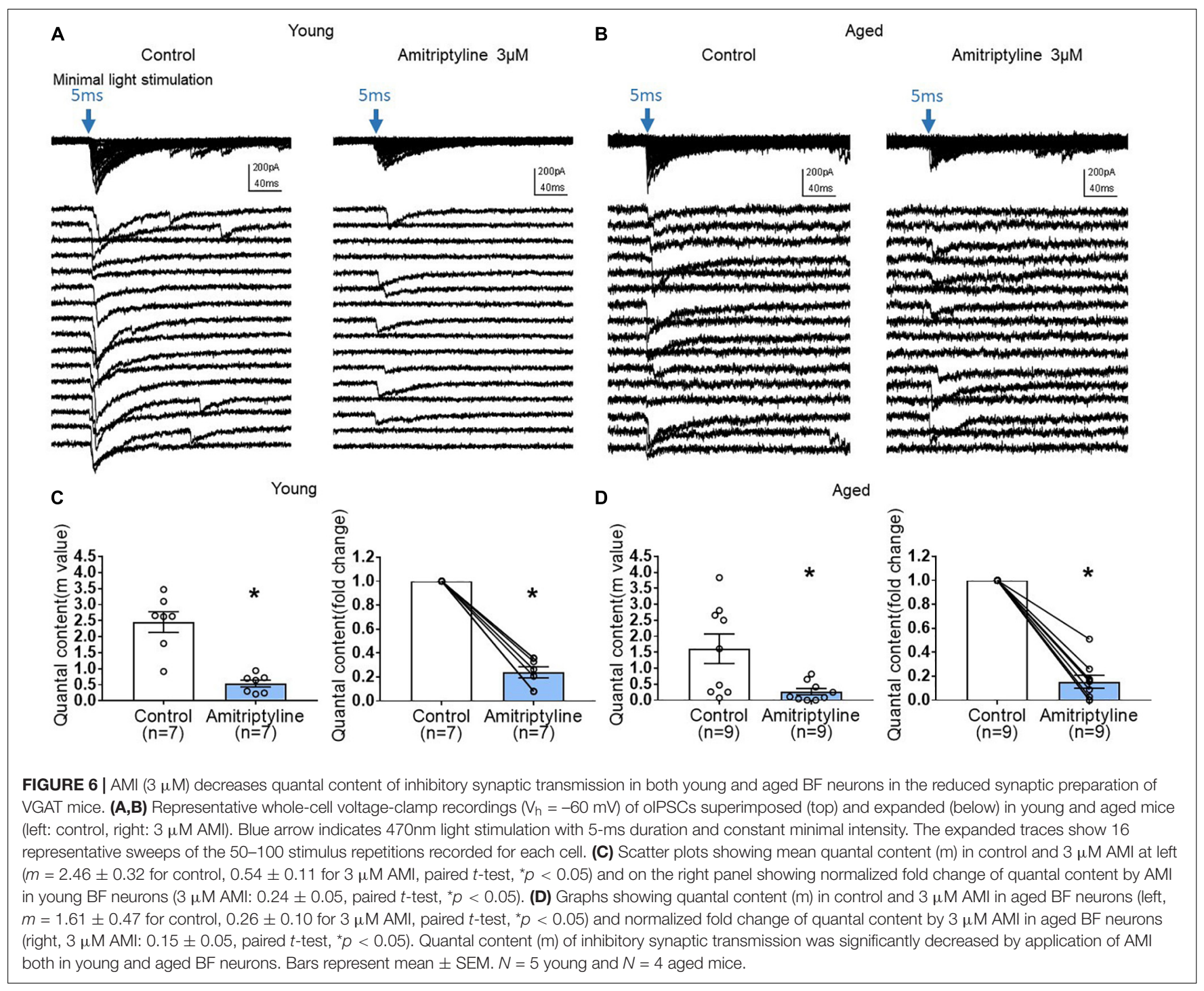

$0.63 \mathrm{mM}$ (Stepanenko et al., 2019). These actions on the NMDA receptor provide a likely mechanism for results showing that AMI inhibited the NMDA-dependent LTP in the hippocampus (Watanabe et al., 1993). Also, the Stepanenko study reported an $\mathrm{IC}_{50}$ value of $4.9 \mu \mathrm{M}$ in $[2 \mathrm{mM}] \mathrm{Ca}^{2+}$ that is very similar to the concentration used in our experiments (Figures 4-6) and suggests that AMI may mediate important actions to regulate neurotransmitters by a mechanism that does not involve voltagegated channels. However, a slight inhibition of presynaptic $\mathrm{I}_{\mathrm{Ca}}$ cannot be ruled out, as concentrations of AMI as low as $1 \mu \mathrm{M}$ have been shown to modestly inhibit $\mathrm{I}_{\mathrm{Ca}}$ in trigeminal ganglion neurons (Wu et al., 2012).

The probability of neurotransmitter release is directly proportional to the $\mathrm{Ca}^{2+}$ change within the synaptic terminal (Zucker, 1993; Wu and Saggau, 1997) and AMI regulation of synaptic transmission by this mechanism has been shown using mechanically isolated medullary dorsal horn neurons (Cho et al., 2012). Here, glycinergic neurotransmission is enhanced by higher concentrations of AMI $(30 \mu \mathrm{M})$ through a suggested presynaptic mechanism to increase neurotransmitter release. These authors provide evidence that AMI increases spontaneous miniature glycinergic IPSCs onto acutely isolated neurons by increasing the interterminal $\mathrm{Ca}^{2+}$ concentration, which might be mediated by the $\mathrm{Ca}^{2+}$ release from the $\mathrm{Ca}^{2+}$ stores rather than the $\mathrm{Ca}^{2+}$ influx from the extracellular space (Cho et al., 2012). Chronic AMI (and other antidepressant) treatments have been shown to affect synaptic plasticity in the hippocampus (Zarei et al., 2014; Zhang et al., 2020) with fewer studies focusing on the acute actions of AMI to regulate synaptic transmission (Watanabe et al., 1993). It is interesting to speculate that, in our study, AMI may decrease the frequency of sIPSCs by a mechanism that regulates intraterminal $\mathrm{Ca}^{2+}$ stores. We did not measure directly the change in intraterminal $\mathrm{Ca}^{2+}$ concentrations induced by AMI, but did not observe a change in somatic baseline $\left[\mathrm{Ca}^{2+}\right]$ on exposure to either 3 or $30 \mu \mathrm{M}$ AMI (Figure 2). Whereas, presynaptic modulation of neurotransmitter release has been long tied to modulating terminal $\mathrm{Ca}^{2+}$ channels, other mechanisms may also come into play to modulate synaptic 


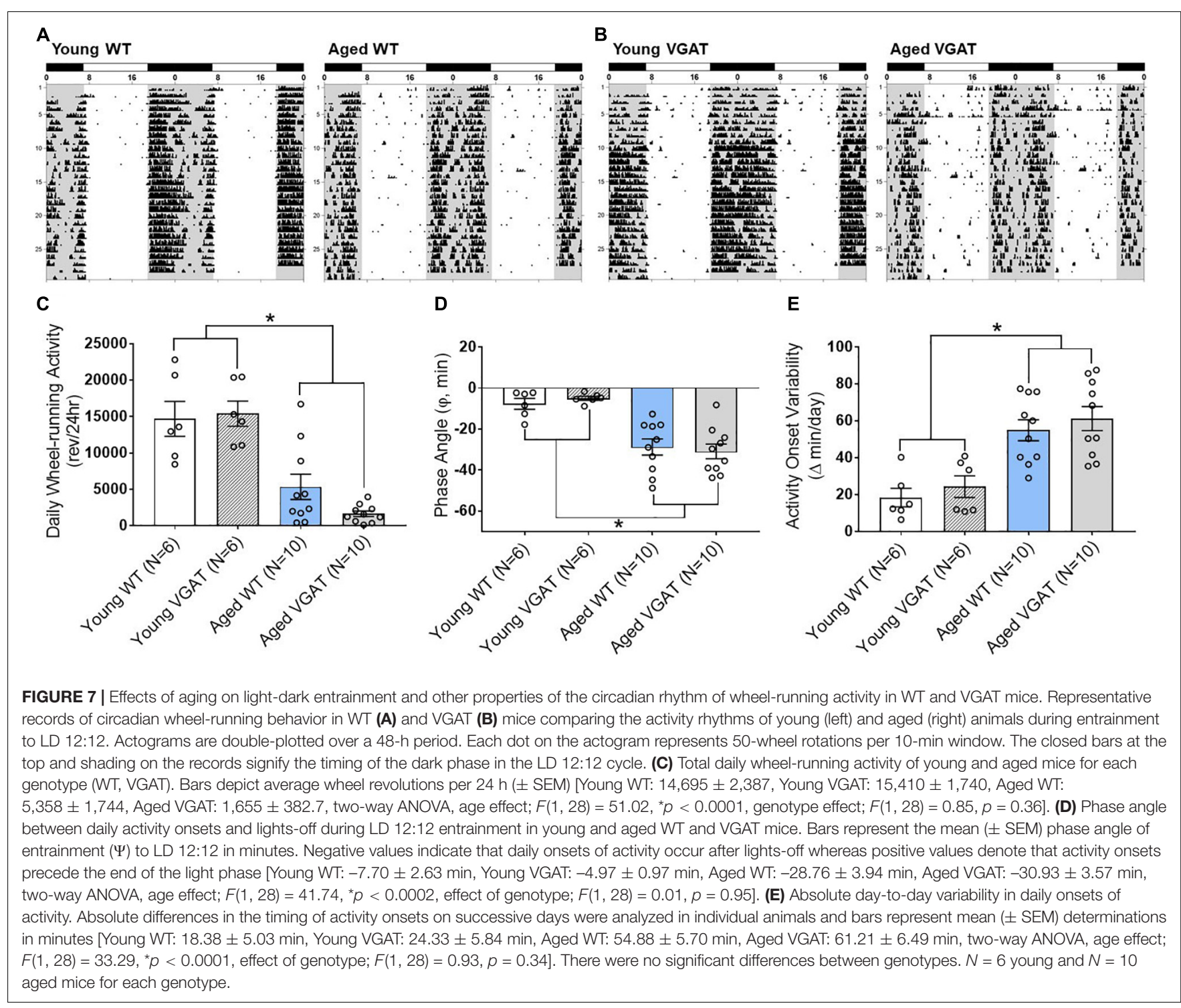

transmission including fast acting neurotropic factors (Berninger and Poo, 1996; Kovalchuk et al., 2004) and transmembrane regulation of synapses (Tang et al., 2016; Biederer et al., 2017; Han et al., 2021).

Neurotrophins have been implicated in the therapeutic effects of antidepressants with brain derived neurotrophic factor (BDNF) acting as one of the most popular candidates (reviewed Dwivedi, 2009; Colucci-D’Amato et al., 2020). Interestingly, AMI possesses neurotrophic effects by acting directly as an agonist of TrkA and TrkB receptors which BDNF triggers (Jang et al., 2009). AMI may exert neurotrophic effects in primary cortical neurons by activation of a Trk/MAPK signaling pathway and possibly alleviating the loss of synaptic connections under conditions where atrophy and loss of synaptic connections may contribute to progression of neurological diseases (O'Neill et al., 2016). Because BDNF has been proposed as a key transducer of the effects of antidepressants (Björkholm and Monteggia, 2016), it is no surprise that the ability of BDNF to rapidly modulate synaptic transmission has been studied extensively (Kim et al., 1994; Berninger and Poo, 1996; Poo, 2001; Kovalchuk et al., 2004). In the hippocampus, BDNF decreases inhibitory GABAergic transmission (Tanaka et al., 1997; Frerking et al., 1998) whereas BDNF increases excitatory transmission (Tyler et al., 2006). This bidirectional control of synaptic transmission by BDNF would be consistent with the observed effects of AMI if it was acting on synaptic transmission through Trk receptors. While our results showed that acute AMI can decrease synaptic transmission by a presynaptic mechanism to decrease quantal release, in cultured organotypic slices of brainstem noradrenergic neurons in the A1 and A2 area, 1-week treatment of $10 \mu \mathrm{M}$ AMI increased quantal size and shifted the distribution of events (Chiti and Teschemacher, 2007). It is possible that AMI either acts directly or indirectly through neurotrophins to regulate synaptic transmission depending upon the specific synapses and releasable pools of transmitter (Tyler et al., 2006). 
Previously, we found that sIPSC frequency in cholinergic $\mathrm{BF}$ neurons is reduced during aging and is associated with cognitive impairment in rats (Griffith et al., 2014). In the present study, AMI decreased the frequency of sIPSCs in young and aged BF neurons of mice. This suggests that AMI could have a negative influence on cognitive function, particularly in the aged. There are numerous studies reporting the effects of AMI on memory and cognitive functions both in humans and in rodent models, however, conclusions differ depending on the experimental conditions. For studies reporting cognitive impairment following AMI treatment, in most cases, a single dose of AMI was administered (Branconnier et al., 1982; Curran et al., 1988; Parra et al., 2002). On the other hand, chronic treatment with AMI demonstrated beneficial effects on cognitive function in clinical and in animal studies (Sternberg and Jarvik, 1976; Staton et al., 1981; Yau et al., 2002; Chadwick et al., 2011). Chronic AMI has been shown to prevent age-related decline and impairment in the water maze task in rats when treatment was initiated at 16 months of age and then tested at 24 months (Yau et al., 2002). These authors suggest that the use of antidepressants may serve as a useful therapeutic approach possibly to ameliorate cognitive impairments in aged individuals.

In our study, we demonstrated that the actions of AMI to reduce synaptic transmission continued during aging in our optogenetic model. We utilized circadian behavioral activity to establish that a parameter of normal aging occurred in this model. Circadian rhythm alterations and disturbances are part of the normal aging process in humans, and these changes in circadian function are further amplified in patients with symptomatic Alzheimer disease (AD) (Witting et al., 1990; Harper et al., 2005). Age- and AD-related changes in circadian rhythms are most pronounced in the sleep-wake cycle (Olivier-Martin et al., 1975; Peter-Derex et al., 2015). Circadian disturbances of sleep-wake rhythms in aging and $\mathrm{AD}$ include rhythm fragmentation over the entire cycle with increased nighttime and decreased daytime bouts of activity in conjunction with a decrease in rhythm amplitude (Weitzman et al., 1982; Satlin et al., 1995; Harper et al., 2005; Peter-Derex et al., 2015; Musiek et al., 2018). In AD, these changes in the sleep-wake cycle are often accompanied by a phase delay in peak daily activity that is associated with an increased risk of moderate to severe dementia (Tranah et al., 2011). The effects of aging on rodent circadian rhythms are comparable to those observed in human aging and $\mathrm{AD}$. Common alterations in the circadian activity of aged rodents include alterations in the amplitude and day-to-day accuracy of the activity rhythm and in its entrainment to light-dark cycles (Rusak and Zucker, 1979; Ingram et al., 1982). Consistent with the age-related changes in sleep-wake rhythms reported in humans and rodents, aged WT and VGAT mice in the present study were distinguished by phase delays and increased day-to-day variability in the activity onsets during entrainment to the daily light-dark cycle. Consequently, these findings establish the utility of the VGATChR2 optogenetic mouse as a model to study the relationship between aging and circadian rhythm disturbances. As such, future studies will determine whether this circadian dysfunction precedes cognitive impairment during aging and thus provide a biomarker of preclinical dementia.
Our lab recently developed a new optogenetic aging model which demonstrated that expression of the channelrhodopsin in the VGAT mouse line remained functional throughout the lifespan of the mice and there is no effect of genotype (wild type versus VGAT-ChR2-EYFP) on aging-related physiological and behavioral properties (Montgomery et al., in submission). Here we present data showing that therapeutically relevant concentrations of AMI inhibited sIPSC frequency in the mouse $\mathrm{BF}$ neurons regardless of animal age. Given that changes in the frequency reflect changes in probability of neurotransmitter release from presynaptic sites, reduction in sIPSC frequency by AMI suggests that AMI is likely to act presynaptically to decrease the probability of spontaneous GABA release on BF neurons. AMI also significantly decreased the amplitude of sIPSCs in young BF neurons but not quite significantly in aged BF neurons. This indicates that AMI may work on both pre- and post-synaptic sites, perhaps with a greater impact at pre-synaptic sites. This conclusion was supported by the findings that AMI significantly decreased the amplitude of light-induced oIPSCs as well as the quantal content in both young and aged BF neurons without agerelated differences. Future studies will be needed to investigate further possible pre-and postsynaptic mechanisms of AMI.

\section{DATA AVAILABILITY STATEMENT}

The original contributions presented in the study are included in the article/supplementary material, further inquiries can be directed to the corresponding author/s.

\section{ETHICS STATEMENT}

The animal study was reviewed and approved by Texas A\&M University accredited AAALAC committee.

\section{AUTHOR CONTRIBUTIONS}

EB: conceptualization, design of study, optogenetic data acquisition, calcium imaging, immunohistochemistry, formal analysis, data curation, visualization, and writing-original draft, review and editing. AT: calcium current data acquisition, methodology, and analysis. KM: formal analysis and writingreview and editing. AF: data and animal curation. DE: methodology, circadian behavior data acquisition, writingoriginal draft, and review and editing. DM: conceptualization, methodology, validation, and writing-review and editing. WG: conceptualization, design of the study, project administration, methodology, validation, writing-original draft, review and editing, supervision, and resources and funding acquisition. All authors contributed to the article and approved the submitted version.

\section{FUNDING}

Funded by NIH grant AG047652 (WG) and the Janell and Joe Marek 57 Alzheimer's Disease Research Fund (WG). 


\section{REFERENCES}

Akaike, N., and Moorhouse, A. J. (2003). Techniques: applications of the nervebouton preparation in neuropharmacology. Trends. Pharmacol. Sci. 24, 44-47. doi: 10.1016/s0165-6147(02)00010-x

Baldessarini, R. J. (2006). Drug therapy of depression and anxiety disorders in Goodman \& Gilman's. The pharmacological basis of therapeutics, 11th Edn. New York, NY: McGraw Hill, 429-459.

Barber, J. B., and Gibson, S. J. (2009). Treatment of chronic non-malignant pain in the elderly. Drug-Safety 32, 457-474. doi: 10.2165/00002018-200932060-00003

Biederer, T., Kaeser, P. S., and Blanpied, T. A. (2017). Transcellular nanoalignment of synaptic function. Neuron. 96, 680-696. doi: 10.1016/j.neuron.2017.10.006

Björkholm, C., and Monteggia, L. M. (2016). BDNF - a key transducer of antidepressant effects. Neuropharmacology. 102, 72-79. doi: 10.1016/j. neuropharm.2015.10.034

Branconnier, R. J., Devitt, D. R., Cole, J. O., and Spera, K. F. (1982). Amitriptyline selectively disrupts verbal recall from secondary memory of the normal aged. Neurobiol. Aging 3, 55-59. doi: 10.1016/0197-4580(82)90061-6

Brau, M. E., Dreimann, M., Olschewski, A., Vogel, W., and Hempelmann, G. (2001). Effect of drugs used for neuropathic pain management on tetrodotoxinresistant $\mathrm{Na}(+)$ currents in rat sensory neurons. Anesthesiology 94, 137-144. doi: 10.1097/00000542-200101000-00024

Berninger, B., and Poo, M. M. (1996). Fast actions of neurotrophic factors. Curr. Opin. Neurobiol. 6, 324-330. doi: 10.1016/s0959-4388(96)80115-2

Chadwick, W., Mitchell, N., Caroll, J., Zhou, Y., Park, S.-S., Wang, L., et al. (2011). Amitriptyline-mediated cognitive enhancement in aged 3XTg Alzheimer's disease mice is associated with neurogenesis and neurotrophic activity. PLoS One 6:e21660. doi: 10.1371/journal.pone.0021660

Chiti, Z., and Teschemacher, A. G. (2007). Exocytosis of norepinephrine at axon varicosities and neuronal cell bodies in the rat brain. FASEB J. 21, 2540-2550. doi: 10.1096/fj.06-7342com

Cho, J. H., Choi, I. S., Lee, M. G., and Jang, I. S. (2012). Effect of amitriptyline on glycinergic transmission in rat medullary dorsal horn neurons. Brain Res. 1455, 10-18. doi: 10.1016/j.brainres.2012.03.030

Colucci-D'Amato, L., Speranza, L., and Volpicelli, F. (2020). Neurotrophic factor BDNF, physiological functions and therapeutic potential in depression, neurodegeneration and brain cancer. Int. J. Mol. Sci. 21:7777. doi: 10.3390/ ijms 21207777

Couch, J. R., Amitriptyline Versus, Placebo Study, and Group. (2011). Amitriptyline in the prophylactic treatment of migraine and chronic daily headache. Headache 51, 33-51. doi: 10.1111/j.1526-4610.2010. 01800.x

Curran, H. V., Sakulsripron, M., and Lader, M. (1988). Antidepressants and human memory: An investigation of four drugs with different sedative and anticholinergic profiles. Psychopharmacology 95, 520-527. doi: 10.1007/ BF00172967

Dwivedi, Y. (2009). Brain-derived neurotrophic factor: role in depression and suicide. Neuropsychiatr. Dis. Treat. 5, 433-449. doi: 10.2147/ndt.s5700

Frerking, M., Malenka, R. C., and Nicoll, R. A. (1998). Brain-derived neurotrophic factor (BDNF) modulates inhibitory, but not excitatory, transmission in the CA1 region of the hippocampus. J. Neurophysiol. 80, 3383-3386. doi: 10.1152/ jn.1998.80.6.3383

Freysoldt, A., Fleckenstein, J., Lang, P. M., Irnich, D., Grafe, P., and Carr, R. W. (2009). Low concentrations of amitriptyline inhibit nicotinic receptors in unmyelinated axons of human peripheral nerve. Br. J. Pharmacol. 158, 797-805. doi: 10.1111/j.1476-5381.2009.00347.x

Glotzbach, R. K., and Preskorn, S. H. (1982). Brain concentrations of tricyclic antidepressants: single-dose kinetics and relationship to plasma concentrations in chronically dosed rats. Psychopharmacology 78, 25-27. doi: 10.1007/ BF00470582

Griffith, W. H., Dubois, D. W., Fincher, A., Peebles, K. A., Bizon, J. L., and Murchison, D. (2014). Characterization of age-related changes in synaptic transmission onto F344 rat basal forebrain cholinergic neurons using a reduced synaptic preparation. J. Neurophysiol. 111, 273-286. doi: 10.1152/jn.00129. 2013

Griffith, W. H., and Murchison, D. A. (1995). Enhancement of GABA-activated membrane currents in aged Fischer 344 rat basal forebrain neurons. J. Neurosci. 15, 2407-2416. doi: 10.1523/JNEUROSCI.15-03-02407.1995
Hajszan, T., Alreja, M., and Leranth, C. (2004). Intrinsic vesicular glutamate transporter 2-immunoreactive input to septohippocampal parvalbumincontaining neurons: novel glutamatergic local circuit cells. Hippocampus 14, 499-509. doi: 10.1002/hipo.10195

Han, W., Shepard, R. D., and Lu, W. (2021). Regulation of GABA Rs by transmembrane accessory proteins. Trends Neurosci. 44, 152-165. doi: 10.1016/ j.tins.2020.10.011

Harper, D. G., Volicer, L., Stopa, E. G., McKee, A. C., Nitta, M., and Satlin, A. (2005). Disturbance of endogenous circadian rhythm in aging and Alzheimer disease. Am. J. Geriatr. Psychiatry 13, 359-368. doi: 10.1176/appi.ajgp.13.5.359

Ingram, D. K., London, E. D., and Reynolds, M. A. (1982). Circadian rhythmicity and sleep: effects of aging in laboratory animals. Neurobiol. Aging 3, 287-297. doi: 10.1016/0197-4580(82)90017-3

Jang, S. W., Liu, X., Chan, C. B., Weinshenker, D., Hall, R. A., Xiao, G., et al. (2009). Amitriptyline is a TrkA and TrkB receptor agonist that promotes TrkA/TrkB heterodimerization and has potent neurotrophic activity. Chem. Biol. 16, 644-656. doi: 10.1016/j.chembiol.2009. 05.010

Kachur, J. F., Allbee, W. E., and Gaginella, T. S. (1988). Antihistaminic and antimuscarinic effects of amitriptyline on guinea pig ileal electrolyte transport and muscle contractility in vitro. J. Pharmacol. Exp. Ther. 245, 455-459.

Kim, H. G., Wang, T., Olafsson, P., and Lu, B. (1994). Neurotrophin 3 potentiates neuronal activity and inhibits gamma-aminobutyratergic synaptic transmission in cortical neurons. Proc. Natl. Acad. Sci. U.S.A. 91, 12341-12345. doi: 10.1073/ pnas.91.25.12341

Kovalchuk, Y., Holthoff, K., and Konnerth, A. (2004). Neurotrophin action on a rapid timescale. Curr. Opin. Neurobiol. 14, 558-563. doi: 10.1016/j.conb.2004. 08.014

Lavoie, P. A., Beauchamp, G., and Elie, R. (1990). Tricyclic antidepressants inhibit voltage-dependent calcium channels and $\mathrm{Na}(+)-\mathrm{Ca} 2+$ exchange in rat brain cortex synaptosomes. Can. J. Physiol. Pharmacol. 68, 1414-1418. doi: 10.1139/ y90-215

Linnoila, M., Johnson, J., Dubyoski, T., Ross, R., Buchsbaum, M., Potter, W. Z., et al. (1983). Effects of amitriptyline, desipramine and zimeldine, alone and in combination with ethanol, on information processing and memory in healthy volunteers. Acta. Psychiatr. Scand. Suppl. 308, 175-181. doi: 10.1111/j.16000447.1983.tb11121.x

Liu, J., Reid, A. R., and Sawynok, J. (2012). Spinal serotonin 5-HT7 and adenosine A1 receptors, as well as peripheral adenosine A1 receptors, are involved in antinociception by systemically administered amitriptyline. Eur. J. Pharmacol. 698, 213-219. doi: 10.1016/j.ejphar.2012.10.042

Manseau, F., Danik, M., and Williams, S. (2005). A functional glutamatergic neurone network in the medial septum and diagonal band area. J. Physiol. 566, 865-884. doi: 10.1113/jphysiol.2005.089664

Moore, R. A., Derry, S., Aldington, D., Cole, P., and Wiffen, P. J. (2015). Amitriptyline for neuropathic pain in adults. Cochrane. Database. Sys. Rev. 7:CD008242. doi: 10.1002/14651858.CD008242.pub3

Murchison, D., and Griffith, W. H. (1996). High-voltage-activated calcium currents in basal forebrain neurons during aging. J. Neurophysiol. 76, 158-174. doi: 10.1152/jn.1996.76.1.158

Murchison, D., and Griffith, W. H. (1998). Increased calcium buffering in basal forebrain neurons during aging. J. Neurophysiol. 80, 350-364. doi: 10.1152/jn. 1998.80.1.350

Murchison, D., and Griffith, W. H. (2007). Calcium buffering systems and calcium signaling in aged rat basal forebrain neurons. Aging Cell 6, 297-305. doi: 10. 1111/j.1474-9726.2007.00293.x

Murchison, D., McDermott, A. N., LaSarge, C. L., Peeble, K. A., Bizon, J. L., and Griffith, W. H. (2009). Enhanced calcium buffering in F344 rat cholinergic basal forebrain neurons is associated with age-related cognitive impairment. J. Neurophysiol. 102, 2194-2207. doi: 10.1152/jn.00301.2009

Musiek, E. S., Bhimasani, M., Zangrilli, M. A., Morris, J. C., Holtzman, D. M., and Ju, Y. S. (2018). Circadian rest-activity pattern changes in aging and preclinical Alzheimer Disease. JAMA Neurol. 75, 582-590. doi: 10.1001/jamaneurol.2017. 4719

National Center for Health Statistics (2007). Health, United States, 2007 with chartbook on trends in the health of Americans. Available online at: https://www. cdc.gov/nchs/data/hus/hus07.pdf (accessed January 5, 2021). 
Nicholson, G. M., Blanche, T., Mansfield, K., and Tran, Y. (2002). Differential blockade of neuronal voltage-gated $\mathrm{Na}(+)$ and $\mathrm{K}(+)$ channels by antidepressant drugs. Eur. J. Pharmacol. 452, 35-48. doi: 10.1016/s0014-2999(02)02239-2

Nojimoto, F. D., Mueller, A., Hebeler-Barbosa, F., Akinaga, J., Lima, V., Kiguti, L. R., et al. (2010). The tricyclic antidepressants amitriptyline, nortriptyline and imipramine are weak antagonists of human and rat alpha1B-adrenoceptors. Neuropharmacology 59, 49-57. doi: 10.1016/j.neuropharm.2010.03.015

Olivier-Martin, R., Cendron, H., and Vallery-Masson, J. (1975). Sleep in the aged subject. Am. Med. Psychol. 1, 77-90.

O’Neill, E., Kwok, B., Day, J. S., Connor, T. J., and Harkin, A. (2016). Amitriptyline protects against TNF- $\alpha$-induced atrophy and reduction in synaptic markers via a Trk-dependent mechanism. Pharmacol. Res. Perspect. 4, e00195. doi: 10.1002/ prp2.195

Pandey, D. K., Mahesh, R., Kumar, A. A., Rao, V. S., Arjun, M., and Rajkumar, R. (2010). A novel 5-HT(2A) receptor antagonist exhibits antidepressantlike effects in a battery of rodent behavioural assays: approaching early-onset antidepressants. Pharmacol. Biochem. Behav. 94, 363-373. doi: 10.1016/j.pbb. 2009.09.018

Parra, A., Everss, E., Monleón, S., Vinader-Caerols, C., and Arenas, M. C. (2002). Effects of acute amitriptyline administration on memory, anxiety and activity in male and female mice. Neurosci. Res. Comm. 31, 135-144. doi: 10.1002/nrc. 10046

Peck, A. W., Bye, C. E., Clubley, M., Henson, T., and Riddington, C. (1979). A comparison of bupropion hydrochloride with dexamphetamine and amitriptyline in healthy subjects. Br. J. Clin. Pharmacol. 7, 469-478. doi: 10. 1111/j.1365-2125.1979.tb00988.x

Peter-Derex, L., Yammine, P., Bastuji, H., and Croisile, B. (2015). Sleep and Alzheimer's disease. Sleep Med. Rev. 19, 29-38. doi: 10.1016/j.smrv.2014.03.007

Poo, M. M. (2001). Neurotrophins as synaptic modulators. Nat. Rev. Neurosci. 2, 24-32. doi: 10.1038/35049004

Richelson, E. (1979). Tricyclic antidepressants and histamine H1 receptors. Mayo. Clin. Proc. 54, 669-674.

Riediger, C., Schuster, T., Barlinn, K., Maier, S., Weitz, J., and Siepmann, T. (2017). Adverse effects of antidepressants for chronic pain: A systematic review and meta-analysis. Front. Neurol. 8:307. doi: 10.3389/fneur.2017.00307

Rusak, B., and Zucker, I. (1979). Neural regulation of circadian rhythms. Physiol. Rev. 59, 449-526. doi: 10.1152/physrev.1979.59.3.449

Satlin, A., Volicer, L., Stopa, E. G., and Harper, D. (1995). Circadian locomotor activity and core-body temperature rhythms in Alzheimer's disease. Neurobiol. Aging 16, 765-771. doi: 10.1016/0197-4580(95)00059-n

Staton, R. D., Wilson, H., and Brumback, R. A. (1981). Cognitive improvement associated with tricyclic antidepressant treatment of childhood major depressive illness. Percept. Mot. Skills 53, 219-234. doi: 10.2466/pms.1981.53. 1.219

Stepanenko, Y. D., Boikov, S. I., Sibarov, D. A., Abushik, P. A., Vanchakova, N. P., Belinskaia, D., et al. (2019). Dual action of amitriptyline on NMDA receptors: enhancement of Ca-dependent desensitization and trapping channel block. Sci. Rep. 9:19454. doi: 10.1038/s41598-019-56072-z

Sternberg, D. E., and Jarvik, M. E. (1976). Memory functions in depression. Arch. Gen. Psychiatr. 33, 219-224. doi: 10.1001/archpsyc.1976.01770020055009

Suga, T., Takenoshita, M., Watanabe, T., Tu, T. T., Mikuzuki, L., Hong, C., et al. (2019). Therapeutic dose of amitriptyline for older patients with burning mouth syndrome. Neuropsychiatr. Dis. Treat. 15, 3599-3607. doi: 10.2147/NDT. S235669

Tanaka, T., Saito, H., and Matsuki, N. (1997). Inhibition of GABAA synaptic responses by brain-derived neurotrophic factor BDNF in rat hippocampus. J. Neurosci. 17, 2959-2966. doi: 10.1523/JNEUROSCI.17-09-02959. 1997

Tang, A. H., Chen, H., Li, T. P., Metzbower, S. R., MacGillavry, H. D., and Blanpied, T. A. (2016). A trans-synaptic nanocolumn aligns neurotransmitter release to receptors. Nature 536, 210-214. doi: 10.1038/nature19058

Tranah, G. J., Blackwell, T., Stone, K. L., Ancoli-Israel, S., Paudel, M. L., Ensrud, K. E., et al. (2011). Circadian activity rhythms and risk of incident dementia and mild cognitive impairment in older women. Ann. Neurol. 70, 722-732. doi: 10.1002/ana.22468

Tyler, W. J., Zhang, X. L., Hartman, K., Winterer, J., Muller, W., Stanton, P. K., et al. (2006). BDNF increases release probability and the size of a rapidly recycling vesicle pool within rat hippocampal excitatory synapses. J. Physiol. 574, 787-803. doi: 10.1113/jphysiol.2006.111310

Urquhart, D. M., Wluka, A. E., van Tulder, M., Heritier, S., Forbes, A., Fong, C., et al. (2018). Efficacy of low-dose amitriptyline for chronic low back pain: a randomized clinical trial. JAMA Intern. Med. 178, 1474-1481. doi: 10.1001/ jamainternmed.2018.4222

Wainer, B. H., Levey, A. I., Rye, D. B., Mesulam, M. M., and Mufson, E. J. (1985). Cholinergic and non-cholinergic septohippocampal pathways. Neurosci. Lett. 54, 45-52. doi: 10.1016/s0304-3940(85)80116-6

Watanabe, Y., Saito, H., and Abe, K. (1993). Tricyclic antidepressants block NMDA receptor-mediated synaptic responses and induction of long-term potentiation in rat hippocampal slices. Neuropharmacology 32, 479-486. doi: 10.1016/00283908(93)90173-z

Weitzman, E. D., Moline, M. L., Czeisler, C. A., and Zimmerman, J. C. (1982). Chronobiology of Aging: temperature, sleep-wake rhythms and entrainment. Neurobiol. Aging 3, 299-309. doi: 10.1016/0197-4580(82)90018-5

Witting, W., Kwa, I. H., Eikelenboom, P., Mirmiran, M., and Swaab, D. F. (1990). Alterations in the circadian rest-activity rhythm in aging and Alzheimer's disease. Biol. Psychiatr. 27, 563-572. doi: 10.1016/0006-3223(90)90523-5

$\mathrm{Wu}$, L. G., and Saggau, P. (1997). Presynaptic inhibition of elicited neurotransmitter release. Trends Neurosci. 20, 204-212. doi: 10.1016/s01662236(96)01015-6

Wu, W., Ye, Q., Wang, W., Yan, L., Wang, Q., Xiao, H., et al. (2012). Amitriptyline modulates calcium currents and intracellular calcium concentration in mouse trigeminal ganglion neurons. Neurosci. Lett. 506, 307-311. doi: 10.1016/j.neulet. 2011.11.031

Yan, L., Wang, Q., Fu, Q., Ye, Q., Xiao, H., and Wan, Q. (2010). Amitriptyline inhibits currents and decreases the mRNA expression of voltage-gated sodium channels in cultured rat cortical neurons. Brain Res. 1336, 1-9. doi: 10.1016/j. brainres.2010.04.016

Yau, J. L. W., Noble, J., Hibberd, C., Rowe, W. B., Meaney, M. J., Morris, R. G. M., et al. (2002). Chronic treatment with the antidepressant amitriptyline prevents impairments in water maze learning in aging rats. J. Neurosci. 22, 1436-1442. doi: 10.1523/JNEUROSCI.22-04-01436.2002

Záborszky, L., Gombkoto, P., Varsanyi, P., Gielow, M. R., Poe, G., Role, L. W., et al. (2018). Specific basal forebrain-cortical cholinergic circuits coordinate cognitive operations. J. Neurosci. 38, 9446-9458. doi: 10.1523/JNEUROSCI. 1676-18.2018

Zaborszky, L., Pang, K., Somogyi, J., Nadasdy, Z., and Kallo, I. (1999). The basal forebrain corticopetal system revisited. Ann. N. Y. Acad. Sci. 877, 339-367. doi: 10.1111/j.1749-6632.1999.tb09276.x

Zarei, G., Reisi, P., Alaei, H., and Javanmard, S. H. (2014). Effects of amitriptyline and fluoxetine on synaptic plasticity in the dentate gyrus of hippocampal formation in rats. Adv. Biomed. Res. 3:199. doi: 10.4103/2277-9175.142044

Zhang, M., Liu, Y., Hu, G., Kang, L., Ran, Y., Su, M., et al. (2020). Cognitive impairment in a classical rat model of chronic migraine may be due to alterations in hippocampal synaptic plasticity and N-methyl-Daspartate receptor subunits. Mol. Pain. 16:1744806920959582. doi: 10.1177/ 1744806920959582

Zhao, S., Ting, J. T., Atallah, H. E., Qiu, L., Tan, J., Gloss, B., et al. (2011). Cell type-specific channelrhodopsin-2 transgenic mice for optogenetic dissection of neural circuitry function. Nat. Methods 8, 745-752. doi: 10.1038/nmeth. 1668

Zucker, R. S. (1993). Calcium and transmitter release. J. Physiol. Paris. 87, 25-36. doi: 10.1016/0928-4257(93)90021-k

Conflict of Interest: The authors declare that the research was conducted in the absence of any commercial or financial relationships that could be construed as a potential conflict of interest.

Copyright (c) 2021 Bang, Tobery, Montgomery, Fincher, Earnest, Murchison and Griffith. This is an open-access article distributed under the terms of the Creative Commons Attribution License (CC BY). The use, distribution or reproduction in other forums is permitted, provided the original author(s) and the copyright owner(s) are credited and that the original publication in this journal is cited, in accordance with accepted academic practice. No use, distribution or reproduction is permitted which does not comply with these terms. 